\title{
RESEARCH
}

Open Access

\section{CCL2/CCR2 system in neuroepithelial radial glia progenitor cells: involvement in stimulatory, sexually dimorphic effects of maternal ethanol on embryonic development of hypothalamic peptide neurons}

\author{
Guo-Qing Chang, Olga Karatayev, Devi Sai Sri Kavya Boorgu and Sarah F. Leibowitz* (1)
}

\begin{abstract}
Background: Clinical and animal studies show that alcohol consumption during pregnancy produces lasting behavioral disturbances in offspring, including increased alcohol drinking, which are linked to inflammation in the brain and disturbances in neurochemical systems that promote these behaviors. These include the neuropeptide, melanin-concentrating hormone $(\mathrm{MCH})$, which is mostly expressed in the lateral hypothalamus (LH). Maternal ethanol administration at low-to-moderate doses, while stimulating $\mathrm{MCH}$ neurons without affecting apoptosis or gliogenesis, increases in LH the density of neurons expressing the inflammatory chemokine C-C motif ligand 2 (CCL2) and its receptor CCR2 and their colocalization with $\mathrm{MCH}$. These neural effects associated with behavioral changes are reproduced by maternal CCL2 administration, reversed by a CCR2 antagonist, and consistently stronger in females than males. The present study investigates in the embryo the developmental origins of this CCL2/CCR2mediated stimulatory effect of maternal ethanol exposure on $\mathrm{MCH}$ neurons.

Methods: Pregnant rats from embryonic day 10 (E10) to E15 during peak neurogenesis were orally administered ethanol at a moderate dose ( $2 \mathrm{~g} / \mathrm{kg} /$ day) or peripherally injected with CCL2 or CCR2 antagonist to test this neuroimmune system's role in ethanol's actions. Using real-time quantitative $P C R$, immunofluorescence histochemistry, in situ hybridization, and confocal microscopy, we examined in embryos at E19 the CCL2/CCR2 system and $\mathrm{MCH}$ neurons in relation to radial glia progenitor cells in the hypothalamic neuroepithelium where neurons are born and radial glia processes projecting laterally through the medial hypothalamus that provide scaffolds for neuronal migration into LH.
\end{abstract}

(Continued on next page)

* Correspondence: leibow@rockefeller.edu

The Rockefeller University, 1230 York Avenue, New York, NY 10065, USA

C C The Author(s). 2020 Open Access This article is licensed under a Creative Commons Attribution 4.0 International License, which permits use, sharing, adaptation, distribution and reproduction in any medium or format, as long as you give appropriate credit to the original author(s) and the source, provide a link to the Creative Commons licence, and indicate if changes were made. The images or other third party material in this article are included in the article's Creative Commons licence, unless indicated otherwise in a credit line to the material. If material is not included in the article's Creative Commons licence and your intended use is not permitted by statutory regulation or exceeds the permitted use, you will need to obtain permission directly from the copyright holder. To view a copy of this licence, visit http://creativecommons.org/licenses/by/4.0/. The Creative Commons Public Domain Dedication waiver (http://creativecommons.org/publicdomain/zero/1.0/) applies to the data made available in this article, unless otherwise stated in a credit line to the data. 
(Continued from previous page)

Results: We demonstrate that maternal ethanol increases radial glia cell density and their processes while stimulating the CCL2/CCR2 system and these effects are mimicked by maternal administration of CCL2 and blocked by a CCR2 antagonist. While stimulating CCL2 colocalization with radial glia and neurons but not microglia, ethanol increases $\mathrm{MCH}$ neuronal number near radial glia cells and making contact along their processes projecting into $\mathrm{LH}$. Further tests identify the CCL2/CCR2 system in NEP as a primary source of ethanol's sexually dimorphic actions.

Conclusions: These findings provide new evidence for how an inflammatory chemokine pathway functions within neuroprogenitor cells to mediate ethanol's long-lasting, stimulatory effects on peptide neurons linked to adolescent drinking behavior.

Keywords: Maternal ethanol administration, Radial glia progenitor cells, Neuroimmune-neuropeptide interactions, CCL2/CCR2 chemokine system, Melanin-concentrating hormone (MCH) neurons, Neuroepithelium, Lateral

hypothalamus, Sexual dimorphism

\section{Background}

There is strong clinical and preclinical evidence showing that maternal consumption or administration of ethanol during pregnancy has marked effects on brain development and behavioral function in offspring, contributing to an increased risk for alcohol use disorder [1-5]. While chronic ethanol at higher doses causes morphological and functional defects in neural development throughout the brain [6,7], lower doses actually stimulate neurogenesis while having minimal impact on apotosis and astrocytes [8-11]. Maternal intraoral administration of ethanol in rat, at low-to-moderate doses from embryonic day 10 (E10) to E15 during peak hypothalamic neurogenesis, increases in the offspring the density of neurons in the lateral hypothalamus (LH) that express the orexigenic neuropeptide, melaninconcentrating hormone $(\mathrm{MCH})[11,12]$, which is known to have a role in reward and motivated behavior $[13,14]$. This stimulatory effect on $\mathrm{MCH}$ is accompanied by behavioral changes, including increased alcohol consumption $[11,15]$, which are also induced in rats by central injection of $\mathrm{MCH}$ itself [16-18].

With ethanol exposure also stimulating inflammatory chemokines in different brain regions [19-22], these $\mathrm{MCH}$ neurons in the $\mathrm{LH}$ are of particular interest since they colocalize the inflammatory chemokine $\mathrm{C}-\mathrm{C}$ motif ligand 2 (CCL2) and its primary receptor CCR2 [23]. Our recent studies demonstrate in adolescent offspring that maternal ethanol, while increasing neurogenesis, stimulates CCL2 and CCR2 and their expression in almost all $\mathrm{MCH}$ neurons, together with an increase in alcohol drinking $[11,15]$. These neural and behavioral effects are reproduced by maternal administration of CCL2 and blocked by a CCR2 receptor antagonist, supporting the involvement of CCL2/CCR2 signaling in mediating ethanol's actions. They are also sexually dimorphic during adolescence, consistently stronger in females than males. Of particular note is that these effects of ethanol in the LH of adolescent offspring are similarly detected in the embryo, where maternal ethanol exposure similarly increases the density of CCL2 and CCR2 cells and their colocalization in $\mathrm{MCH}$ neurons more consistently in females and these effects are blocked by maternal administration of a CCL2 antibody and CCR2 receptor antagonist, suggesting an important role for this neuroimmune system in the early development of $\mathrm{MCH}$ neurons in the LH [12].

The goal of this study was to investigate where and how ethanol acts in the embryo to affect the development of both the CCL2/CCR2 system and MCH neurons. We focused our analysis on the hypothalamic neuroepithelium (NEP) along the third ventricle where neurons are born [24]. In this area, we examined the radial glia progenitor cells, which play fundamental roles in patterning and differentiation of the developing CNS and are pluripotent, serving as primary progenitors to both neurons and glia including astroglia $[25,26]$. They additionally provide long extended processes or scaffolds that guide migrating neurons from their site of differentiation to their terminal locations, thereby determining their density, distribution, and patterning [24, 27-29]. While high doses of ethanol are shown to reduce the density and disturb the morphology of radial glia and disrupt their function in promoting the differentiation and migration of neurons [30,31], we used here the radial glia marker, brain lipid-binding protein (BLBP), to examine how a lower dose of ethanol that stimulates neurogenesis affects these radial glia cells in the hypothalamic NEP and their processes that project laterally through the medial hypothalamus (mHYP) toward the LH. With studies showing the CCL2/CCR2 system to be expressed in neural progenitor cells of the spinal cord [32] and to stimulate neuronal differentiation and migration in other brain regions [33-35], we additionally examined after ethanol exposure the relation of this neuroimmune system to radial glia cells in the hypothalamic NEP, their processes in the MHYP, and the density and patterning of $\mathrm{MCH}$ neurons as they migrate from the NEP through the mHYP toward the LH. 
The evidence described in this report suggests the involvement of the embryonic CCL2/CCR2 system in radial glia neuroprogenitor cells of the hypothalamic NEP in mediating ethanol's stimulatory, sexually dimorphic effects in utero on the density of $\mathrm{MCH}$ neurons in the hypothalamus. The significance of these embryonic events lies in the evidence that they are long lasting, with studies in adolescent offspring prenatally exposed to ethanol [11, 15] showing $\mathrm{MCH}$ neurons to be markedly increased in the LH with almost all colocalizing CCL2 and CCR2, a neural change closely linked to disturbances in alcohol-related behaviors.

\section{Methods}

All procedures were conducted in a fully accredited AAALAC facility $\left(22^{\circ} \mathrm{C}, 12: 12\right.$-h light-dark cycle with lights off at $7 \mathrm{am})$, in accordance with protocols approved by The Rockefeller University Animal Care and Use Committee and consistent with the NIH Guide to the Care and Use of Laboratory Animals.

\section{Animals}

Time-pregnant, Sprague-Dawley rats (220-240 g) (Charles River Breeding Laboratories, Hartford, CT) arrived at the facility on embryonic day 5 (E5) and were acclimated to the laboratory conditions until E10, at which time experiments began as described in detail below. In all experiments, rodent chow (LabDiet Rodent Chow 5001, St. Louis, MO) and filtered water were available ad libitum. As described in the Experimental Design section below, all female and male embryos were sacrificed at E19, the age before birth used in our prior study of the embryo [12] when $\mathrm{MCH}$ neurons in the LH first exhibit an adult-like pattern [36], with 1 male and 1 female pup taken from each litter and the number of rats/ sex/group $(n=6-7)$ equal to the number of litters/ group.

\section{Maternal administration of ethanol}

Pregnant rats ( $n=6-7$ /experiment) were intraorally administered, from E10-E15 when $\mathrm{MCH}$ neurons develop in the hypothalamus [36], either a $2 \mathrm{~g} / \mathrm{kg} /$ day ethanol solution ( $30 \% \mathrm{v} / \mathrm{v})$ ("Ethanol") or a control solution of maltose-dextrin made isocaloric to the ethanol solution ("Control") [9], with an additional group of pregnant rats that were untreated controls ("Untreated"). The daily dose of ethanol was split in half with all rats gavaged twice daily, with the first gavage of $1 \mathrm{~g} / \mathrm{kg}$ occurring $2 \mathrm{~h}$ after the start of the dark cycle and the second gavage of this dose occurring $7 \mathrm{~h}$ later. In blood collected from the tail vein at $2 \mathrm{~h}$ after the morning ethanol gavage on E11, blood ethanol concentration (BEC) was measured using Analox GM7 Alcohol Analyzer (Lunenburg, MA, USA) and was elevated to $\sim 80 \mathrm{mg} / \mathrm{dL}$, consistent with previous reports [9, 37]. Since this moderate dose and short period of ethanol exposure in pregnant rats are not expected to produce the symptoms of dependence and withdrawal observed with much higher doses (9-15 $\mathrm{g} / \mathrm{kg} /$ day) and longer periods of exposure in nonpregnant rats $[38,39]$ further tests after removal of ethanol were not performed.

\section{Maternal administration of CCL2}

Building on our recent studies showing administration of CCL2 itself to mimic the stimulatory effects of ethanol on CCL2 and CCR2 in the LH and produce these effects more strongly in females $[11,12]$, we gave pregnant rats $(n=6-7 /$ experiment) one daily injection of CCL2 $(4 \mu \mathrm{g} / \mathrm{kg} /$ day, s.c.), from E10 to E15 at $4 \mathrm{~h}$ into the dark cycle, as compared to its vehicle Control (sterile water) or Untreated controls, and examined its effects in female embryos at E19. This dose of CCL2 was chosen based on our previously published study [11], which is the first to describe the effect of maternal administration of CCL2 on the offspring and to show prenatal administration of CCL2, at 4 as well as $8 \mu \mathrm{g} / \mathrm{kg} /$ day from E10 to E15, to have similar stimulatory effects on the expression and density of CCL2/CCR2 and $\mathrm{MCH}$ expression in neurons.

\section{Maternal administration of CCR2 antagonist}

We additionally tested the effects of maternal administration of the CCR2 receptor antagonist INCB3344 (MedChem Express, Cat. \# HY-50674), previously used in rat studies of inflammation and pain $[40,41]$. In pregnant rats ( $n=6-7 /$ experiment), ethanol ( $2 \mathrm{~g} / \mathrm{kg} /$ day $)$ or its isocaloric control from E10 to E15 were intraorally administrated twice daily as described above. In addition, we injected $30 \mathrm{~min}$ after each ethanol administration either INCB3344 ( $1 \mathrm{mg} / \mathrm{kg} /$ day, s.c.) or its vehicle Control (sterile water) or gave no treatment (Untreated), and female embryos in these groups were examined at E19. This dose of INCB3344 was chosen based on our previously published studies $[11,12]$ showing it to be effective in blocking the stimulatory effects of ethanol on neurons in the LH of adolescent rats and E19 embryos while having no effect on the dam's food intake, water intake, and body weight or on the litter size and pup's body weight at birth.

\section{Quantitative real-time PCR}

Quantitative real-time PCR (qRT-PCR) was used to measure the gene expression of brain lipid-binding protein (BLBP), a radial glia marker [42], along with CCL2, CCR2, and $\mathrm{MCH}$ in the NEP and mHYP of embryos. They were sacrificed at E19, their tails were collected for genotyping to determine sex, and their brains were immediately removed and placed on a microscope slide on 
top of an ice-filled petri dish, with the ventral surface facing up for slicing. The NEP and mHYP areas were combined for the qRT-PCR analysis, based on our preliminary tests showing them separately to yield similar responses to ethanol and them combined to provide a more consistent dissection and more tissue needed for qRT-PCR as described in our recent report [12]. This area, referred to in the text as "NEP+mHYP", was dissected as follows using gem razor blades (American Safety Razor Co., Verona, VA). Two coronal cuts were made, with the anterior cut $0.5 \mathrm{~mm}$ caudal to the posterior edge of the middle optic chiasm (Coronal Plate 10, E20) [43] and the posterior cut $1.0 \mathrm{~mm}$ caudal to the anterior cut (Coronal Plate 10 to 13, E20). After putting this slice on a microscope glass with its posterior level plain facing up, the NEP+mHYP area was further microdissected, with a lateral cut made $0.6 \mathrm{~mm}$ bilateral to hypothalamic third ventricle, a ventral cut made at the dorsal edge of the medial eminence, and a dorsal cut made $0.1 \mathrm{~mm}$ ventral to the fornix.

Total RNA was then extracted from each microdissected sample, cDNA was synthesized, and qRT-PCR was performed, as previously described in our publications $[9,11,44]$ and others $[45,46]$. The primers for BLBP, CCL2, CCR2, and $\mathrm{MCH}$, designed with ABI Primer Express Version 3.0 software from published sequences, and their concentrations are presented in Table 1. The mRNA levels of the target gene in each rat were normalized within subject relative to mRNA levels of the internal house-keeping gene, cyclophilin, in the same sample, and this ratio of target gene expression to house-keeping gene expression was calculated in each rat using the standard delta-delta $\mathrm{Ct}$ method. Then, target gene mRNA levels were averaged in each rat within control and ethanol groups, and the average of the target gene mRNA level in the ethanol group was compared to the level in control. An ANOVA was then run on this ratio calculated for each subject, with the effect of ethanol on target gene expression determined by comparing the average ratio in the experimental groups to the control groups, as well as the control groups with each other. The mRNA data presented in Tables 5 and 6 are an averaged ratio (target gene expression/house-keeping gene expression) in each group, and those presented in the bar graphs of Fig. 2 are presented as fold change for clarity $[11,12]$. The variability we observed in the baseline measures of CCL2, CCR2, and BLBP mRNA levels in the NEP as shown in these tables may be real, as it was confirmed in two separate groups of control embryos, was similarly observed with measures of CCL2 and CCR2 in the LH of adolescent control groups [11, 12], and is consistent with our additional finding with immunofluorescence histochemistry (Table 7) showing the density of BLBP cells in the NEP to be considerably greater than that of the CCL2 cells in this area.

\section{Single- and double-label immunofluorescence histochemistry}

Immunofluorescence histochemistry (IF) was used, as previously described [11, 15, 47], to characterize the distribution pattern and quantify in the embryo at E19 the following: (1) BLBP-immunoreactive $\left(\mathrm{BLBP}^{+}\right)$radial glia progenitor cells; (2) CCL2-immunoreactive $\left(\mathrm{CCL}^{+}\right)$ cells in the NEP, with $\mathrm{CCR}^{+}$cells not detected here at E19 using available antibodies; (3) $\mathrm{BLBP}^{+}$and $\mathrm{CCL}^{+} \mathrm{fi}^{-}$ bers or processes of these NEP cells, which are seen in the mHYP as they project laterally toward the $\mathrm{LH}$ and are longer and more clearly defined for the $\mathrm{BLBP}^{+}$than $\mathrm{CCL}_{2}{ }^{+}$processes; and (4) $\mathrm{MCH}$-immunoreactive $\left(\mathrm{MCH}^{+}\right)$neurons, which in the embryo can be detected although sparsely in the NEP, become denser in the mHYP, and are most dense in the LH. While we also tested GFAP, a marker for astrocytes, we observed few $\mathrm{GFAP}^{+}$cells in the NEP and mHYP of ethanol-exposed and control embryos and no effect of maternal ethanol on these cells, as shown previously in adolescent offspring [11]. The precise areas examined, the NEP and mHYP as they relate to the $\mathrm{LH}$, are illustrated in the DIC image of an embryonic brain section (Fig. 1).

To analyze at $\mathrm{E} 19$ the $\mathrm{BLBP}^{+}, \mathrm{CCL}^{+}$, and $\mathrm{MCH}^{+}$cells in the NEP and the $\mathrm{BLBP}^{+}$and $\mathrm{CCL} 2^{+}$processes in the mHYP using single-labeling IF, the embryos were killed by perfusing their dams intracardially with $0.9 \%$ normal saline followed by $4 \%$ paraformaldehyde in phosphate buffer (PB), their tails were collected for genotyping to determine the sex, and their brains were removed and

Table 1 Primers for measurements of mRNA levels using qRT-PCR

\begin{tabular}{lllll}
\hline Gene & GenBank accession & Forward 5'-3' & Reverse 5'-3' & Concentration (nM) \\
\hline Cyclophilin & NM_001004279 & TGTGCTGAATATTGGTGCTTGTAA & TGTGCTGAATATTGGTGCTTGTAA & 200 \\
BLBP & NM_030832 & TGATTCGGTTGGATGGAGACA & CGACATCCCCAAAGGTGAGA & 200 \\
CCL2 & NM_031530 & GTG CTG TCT CAG CCA GAT GCA GTT & AGT TCT CCA GCC GAC TCA TTG GG & 200 \\
CCR2 & NM_021866 & TAC CTG TTC AAC CTG GCC ATC T & AGA CCC ACT CAT TTG CAG CAT & 200 \\
MCH & M_029712 & CAAACAGGATGGCGAAGATGA & AGGCTTTCCCCATCCTGAAT & 50
\end{tabular}

BLBP brain lipid-binding protein, CCL2 C-C motif ligand 2, CCR2 receptor for CCL2, MCH melanin-concentrating hormone 


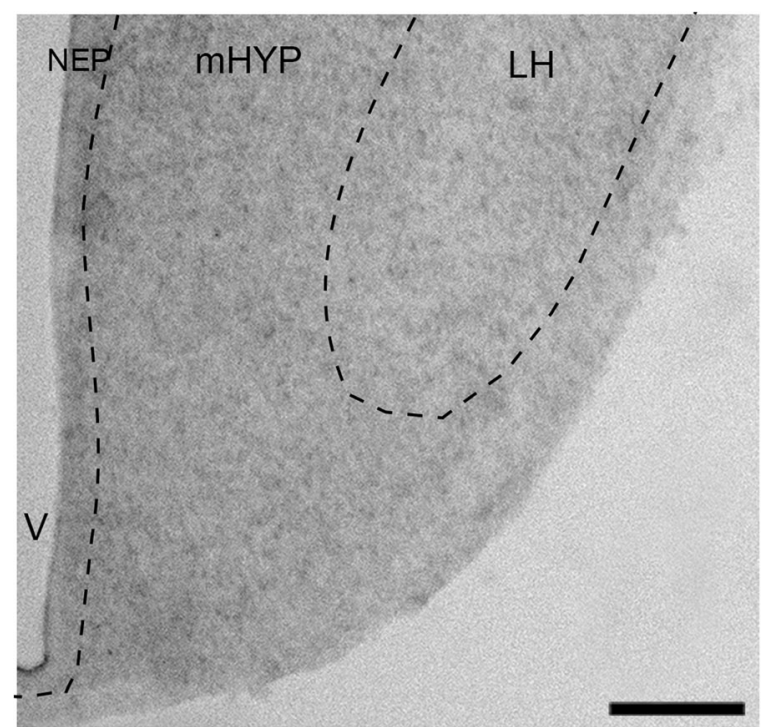

Fig. 1 DIC image $(\times 2.5)$ illustrates in E19 embryo the three hypothalamic regions investigated in this manuscript. It shows from medial to lateral the hypothalamic neuroepithelium (NEP) along the third ventricle $(V)$, the medal hypothalamus (mHYP) immediately lateral to the NEP, and the lateral hypothalamus (LH). Scale bar $200 \mu \mathrm{m}$

post-fixed for $4 \mathrm{~h}$ in the same fixative at $4{ }^{\circ} \mathrm{C}$, cryoprotected in $25 \%$ sucrose at $4^{\circ} \mathrm{C}$ for $72-96 \mathrm{~h}$, and then frozen and stored at $-80^{\circ} \mathrm{C}$. Brains were cut at $30 \mu \mathrm{m}$ with a cryostat, and free-floating coronal sections were processed with the primary antibodies and their corresponding secondary antibodies listed in Table 2.

Sections were viewed, and fluorescence images were captured using a Zeiss LSM 880 confocal microscope with $a \times 20$ objective. For quantitation, the images of the NEP and mHYP illustrated in Fig. 1 were outlined and analyzed. For each embryo, 8-10 images were collected at the anterior-posterior level of coronal plates 12 to 13 in E20 brains [43]. The density of single-label immunofluorescent cells in the NEP was then quantified, using Image-Pro Plus software (Version 4.5; Media Cybernetics) as previously described $[11,15,47]$. Only intact cells with an area of $50-100 \mu \mathrm{m}^{2}$ were counted, and the population density of these cells in the NEP is reported as cells $/ \mu \mathrm{m}^{2}$. The measure in the mHYP recorded as objects $/ \mu \mathrm{m}^{2}$ reflects mostly the fibers of the $\mathrm{BLBP}^{+}$and $\mathrm{CCL}^{+}$cells which we found to be dense in this area where few cells are evident, leading us to refer to these objects as "processes" in the text.

Double-labeling IF was used to determine whether CCL2 in the NEP and MHYP of the embryo colocalizes with the radial glial marker BLBP in its cells and processes, as well as with the neuronal marker NeuN and microglia marker Iba-1 in these cells, and also whether the $\mathrm{MCH}$ neurons are anatomically associated with the BLBP radial glia cells and processes. This double labeling was performed using a combination of primary antibodies and their corresponding secondary antibodies listed in Table 3, based on our procedures described previously $[11,15,47]$.

For this analysis of double-labeling, the images were captured by a Zeiss LSM 880 confocal microscope with $\times 20$ objective, and the double-labeling was further confirmed by Z-stack sectioning with a $\times 40$ oil-immersion lens, with the Z-stacks $30 \mu \mathrm{m}$ thick and the step size of $0.7-0.8 \mu \mathrm{m}$ for optimal stack collection and analysis. In all analyses, the cells and processes were counted in each section, and only the cells of a designated size (area of $50-100 \mu \mathrm{m})$ were counted. The double-labeled cells counted in $\times 20$ images and double-labeled processes counted in $\times 40$ images are reported as the percentage of total single-labeled cells or processes, respectively. Some variability in CCL2 staining, while not evident with single labeling, sometimes occurred when the CCL2 antibody was co-labeled with other antibodies, particularly for NeuN and Iba-1, but not for BLBP. To confirm that the $\mathrm{BLBP}^{+}$and $\mathrm{CCL} 2^{+}$cells in the NEP are epithelial cells, we used DAPI to stain the nucleus. The doublelabeling of cells with DAPI and BLBP or CCL2 in the NEP was confirmed by confocal Z-Stack sectioning, as demonstrated in Figs. 4 and 5 showing that almost all of the radial glia cells and CCL2 cells contain a nucleus and thus are epithelial in nature. To confirm that the $\mathrm{BLBP}^{+}$and CCL2 ${ }^{+}$cells in the NEP are epithelial cells, we used DAPI to stain the nucleus. Confocal Z-Stack sectioning $(30 \mu \mathrm{m}$ thick and step size of $1.02 \mu \mathrm{m})$ of double-staining of DAPI with BLBP or CCL2 in the NEP

Table 2 Antibodies used for single-labeling immunofluorescence histochemistry

\begin{tabular}{llllll}
\hline Primary antibody & Dilution & Vendor & Secondary antibody & Dilution & Vendor \\
\hline Rabbit anti-CCL2 & $1: 200$ & Biorbyt, CA & $\begin{array}{l}\text { Bio-Horse anti-Rabbit IgG + TSA } \\
\text { Fluorescein }\end{array}$ & 1:100 & Vector, CA \\
Rabbit anti-BLBP & $1: 200$ & Abcam, MA & Cy3-Donkey anti-Rabbit IgG & $1: 100$ & $\begin{array}{l}\text { Jackson ImmunoResearch } \\
\text { Laboratories Inc, PA }\end{array}$ \\
Rabbit anti-MCH & $1: 1000$ & Phoenix Pharmaceuticals, CA & Cy3-Donkey anti-Rabbit IgG & $1: 100$ & Jackson ImmunoResearch \\
& & & & Laboratories. Inc, PA \\
\hline
\end{tabular}


Table 3 Antibodies used for double-labeling immunofluorescence histochemistry

\begin{tabular}{|c|c|c|c|c|c|c|}
\hline Combination & Primary antibody & Dilution & Vendor & Secondary antibody & Dilution & Vendor \\
\hline \multirow[t]{2}{*}{$\mathrm{CCL2+BLBP}$} & Rabbit anti-CCL2 & $1: 200$ & Biorbyt, CA & $\begin{array}{l}\text { Bio-Horse anti-Rabbit lgG + } \\
\text { TSA Fluorescein }\end{array}$ & $1: 100$ & Vector, CA \\
\hline & Mouse anti-BLBP & $1: 200$ & Abcam, MA & Cy3-Donkey anti-Mouse IgG & $1: 100$ & $\begin{array}{l}\text { Jackson ImmunoResearch } \\
\text { Laboratories. Inc, PA }\end{array}$ \\
\hline \multirow[t]{2}{*}{$\mathrm{CCL} 2+\mathrm{NeuN}$} & Rabbit anti-CCL2 & $1: 200$ & Biorbyt, CA & $\begin{array}{l}\text { Bio-Horse anti-Rabbit lgG + } \\
\text { TSA Fluorescein }\end{array}$ & 1:100 & Vector, CA \\
\hline & Mouse anti-NeuN & $1: 100$ & EMD Millipore, MA & Cy3-Donkey anti-Mouse IgG & 1:100 & $\begin{array}{l}\text { Jackson ImmunoResearch } \\
\text { Laboratories. Inc, PA }\end{array}$ \\
\hline \multirow[t]{2}{*}{$C C L 2+l b a-1$} & Rabbit anti-CCL2 & $1: 200$ & Biorbyt, CA & $\begin{array}{l}\text { Bio-Horse anti-Rabbit lgG + } \\
\text { TSA Fluorescein }\end{array}$ & $1: 100$ & Vector, CA \\
\hline & Goat anti-lba-1 & $1: 200$ & Abcam, MA & Cy3-Donkey anti-Goat lgG & 1:100 & $\begin{array}{l}\text { Jackson ImmunoResearch } \\
\text { Laboratories. Inc, PA }\end{array}$ \\
\hline \multirow[t]{2}{*}{$\mathrm{MCH}+\mathrm{BLBP}$} & Rabbit anti-MCH & $1: 1000$ & Phoenix Pharmaceuticals, CA & FITC-Donkey anti-Rabbit lgG & $1: 50$ & $\begin{array}{l}\text { Jackson ImmunoResearch } \\
\text { Laboratories. Inc, PA }\end{array}$ \\
\hline & Mouse anti-BLBP & $1: 200$ & Abcam, MA & Cy3-Donkey anti-Mouse IgG & 1:100 & $\begin{array}{l}\text { Jackson ImmunoResearch } \\
\text { Laboratories. Inc, PA }\end{array}$ \\
\hline
\end{tabular}

CCL2 C-C motif ligand 2, BLBP radial glia marker brain lipid-binding protein, NeuN neuronal marker, lba-1 microglia marker, $M C H$ melanin-concentrating hormone

shown in Figs. 4 and 5 that almost all of the radial glia cells and CCL2 cells contain a nucleus, confirming that they are epithelial in nature.

\section{Digoxigenin-labeled in situ hybridization histochemistry for $\mathrm{MCH}$}

We performed digoxigenin-labeled in situ hybridization histochemistry (DIG-ISH) to investigate $\mathrm{MCH}^{+}$neurons in the NEP and mHYP of E19 embryos and to determine their anatomical relationship to the $\mathrm{BLBP}^{+}$radial glia cells and processes in these areas. Briefly, as previously described [47], DIG-labeled RNA probes and $30 \mu \mathrm{m}$ free-floating cryostat coronal sections were employed, and AP-conjugated sheep anti-digoxigenin Fab fragments (1:1000; Roche Diagnostics, Indianapolis, IN, USA) and NBT/BCIP (Roche Diagnostics) were used to visualize $\mathrm{MCH}$-expressing neurons (see Fig. 8b). A negative control was performed with a sense probe, which revealed no $\mathrm{MCH}$-expressing neurons in the area extending from the NEP to the LH, and a positive control was performed in the $\mathrm{LH}$ where $\mathrm{MCH}$-expressing neurons are known to be most heavily expressed, as previously described $[48,49]$. Sections were viewed on a Leitz microscope ( $\times 10$ objective). The images were captured with a Nikon DXM 1200 digital camera (Nikon, Tokyo, Japan) and analyzed using Image-Pro Plus software (Version 4.5, Media Cybernetics Inc., Silver Spring, MD, USA) on a gray-value scale from 1 to 255 . In each animal, 8-10 sections at the same level were used to examine the NEP and MHYP, and the entire area was outlined and analyzed as described [11, 15, 47]. The population density was used to determine the cell density in these two areas, with a few $\mathrm{MCH}^{+}$neurons detected in the NEP and a denser concentration seen in the mHYP.

To determine whether these $\mathrm{MCH}^{+}$neurons in the NEP and mHYP are related to the radial glia cells and processes, we performed double-labeling by combining DIGISH for $\mathrm{MCH}^{+}$neurons with IF for $\mathrm{BLBP}^{+}$radial glia in these areas of the E19 embryo brain. After the MCH signal was first visualized in NBT/BCIP, the sections were briefly washed in $0.1 \mathrm{M}$ Tris- $\mathrm{HCl}$ containing $0.1 \mathrm{M} \mathrm{NaCl}$ and $50 \mathrm{mM} \mathrm{MgCl} 2$ (pH 9.5) and PBS. They were then processed for BLBP IF as described above, and FITCDonkey anti-Rabbit IgG (1:50, Jackson ImmunoResearch Laboratories, Inc. PA) was used to reveal BLBP labeling. To verify the specificity of the double-labeling, the following controls were performed (see Fig. 9a): (1) MCH sense probe negative control: sense probe was used for $\mathrm{MCH}$ DIG-ISH in the double-labeling, which revealed no $\mathrm{MCH}$ expression without affecting BLBP immunofluorescence; (2) no secondary fluorescence antibody control: the secondary antibody, FITC-Donkey anti-Rabbit IgG, was omitted in the double-labeling, which revealed no BLBP immunofluorescence without affecting $\mathrm{MCH}$ expression; and (3) positive control: the double-labeling was performed in the NEP, mHYP, and $\mathrm{LH}$ where both $\mathrm{MCH}$ and BLBP are heavily expressed. Double-labeling of $\mathrm{MCH}$ with BLBP cells in the NEP and of MCH cells with BLBP processes in the mHYP was quantified, as described above. In addition, the number of $\mathrm{MCH}$ cells positioned along and closely contacting BLBP processes in the mHYP as they projected laterally toward the LH were counted manually in each image, and the percentage of these neurons relative to the total number of $\mathrm{MCH}$ neurons in the mHYP was determined. 


\section{Statistical analysis}

All data were collected and analyzed in a blinded fashion using SPSS (Version 23), and they are presented as mean \pm SEM. All graphs were prepared using the GraphPad Prism software (Version 6). Data in experiments using female and male embryos were analyzed using a twoway ANOVA, which tested between-subject main effects of maternal ethanol treatment and sex, and the interactions between these two factors. A significant interaction was interpreted using simple main effect analyses to test the differences between sexes as well as the differences within each sex. Data in experiments examining the effect of maternal treatment on bodyweight of dams and embryos, dam's chow intake and litter size as well as those experiments where only female embryos were analyzed using a one-way ANOVA, which tested the effects of maternal administration of ethanol, CCL2 or CCR2 antagonist on the different measures of BLBP, CCL2 and $\mathrm{MCH}$, followed by LSD post hoc tests. Paired $t$ tests were performed to directly compare the effects of maternal treatment vs control groups within each sex and the effects of maternal ethanol to isocaloric control when only two groups in one sex were examined.

\section{Results}

Maternal ethanol administration increases BLBP mRNA in $\mathrm{NEP}+\mathrm{mHYP}$ more strongly in female than male embryos

Our first step was to determine whether maternal ethanol alters the expression of BLBP in the NEP $+\mathrm{mHYP}$ of embryos and whether this effect differs between the sexes. Using qRT-PCR, we tested the effects of maternal intraoral ethanol administration compared to Control and Untreated control groups of female and male embryos and found a significant main effect of ethanol treatment $(F(2,36)=39.36, p<0.001)$, in addition to an effect of $\operatorname{sex}(F(1,36)=20.73, p<0.001)$ and a sex $x$ treatment interaction $(F(2,36)=9.96, p<0.001)$ (Fig. 2). While there were no differences between respective control groups of females and males, the BLBP expression was higher in ethanol-exposed females compared to ethanol-exposed males $(p<0.001)$. Furthermore, ethanol significantly increased BLBP mRNA levels in both sexes compared to the Control $(p<0.001$ for female and $p=$ 0.004 for male) and Untreated $(p<0.001$ for female and $p=0.018$ for male) groups, with this effect significantly greater in females than males $(t(12)=3.49, p=0.004)$. There was no significant main effect of maternal ethanol on the bodyweight of dams at $\mathrm{E} 19(F(2,18)=0.456, p=$ $0.641)$ and their E19 embryos $(F(2,18)=1.117, p=$ $0.349)$ and also no effect on dam's daily chow intake $(F(2,18)=1.156, p=0.337)$ and litter size $(F(2,18)=$ $0.405, p=0.405$ ) (Table 4$)$. Together, these results show that maternal ethanol administration at a moderate dose has a stimulatory effect on the expression of radial glia

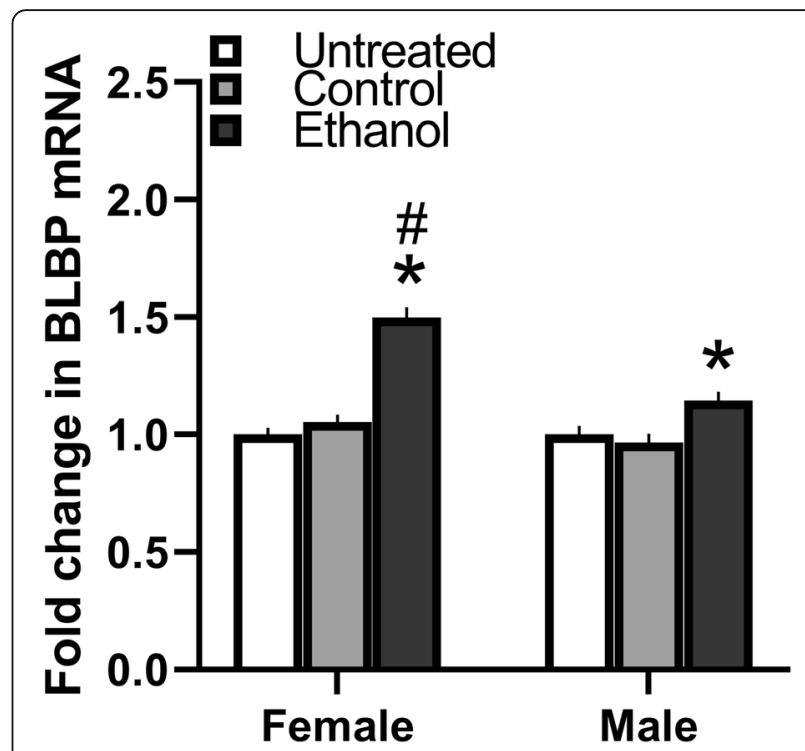

Fig. 2 Effects of ethanol on expression of BLBP in NEP and $m$ HYP. Maternal ethanol administration group (2 g/kg/day, E10-E15) was compared to Untreated and isocaloric Control groups of E19 embryos. Ethanol significantly increased in NEP+mHYP area the expression of BLBP measured using $\mathrm{QRT} T \mathrm{PCR}$, which is presented here as mRNA fold change compared to the Untreated control group. This effect on BLBP mRNA levels (with analysis of average ratio scores) was evident in both female embryos (Untreated $=0.223$ \pm 0.006 , Control $=0.234 \pm 0.007$, Ethanol $=0.334 \pm 0.014$ ) and male embryos (Untreated $=0.221 \pm 0.008$, Control $=0.214 \pm 0.008$,

Ethanol $=0.253 \pm 0.009$ ) but was significantly greater in females, with no differences between female and male control groups and between control groups within each sex. Data are mean \pm SEM. $(n=$ $7 /$ group/sex, ${ }^{*} p<0.05$ versus control group, ${ }^{*} p<0.05$ versus males). Two-way ANOVA was used to compare means between groups, simple main effect analyses to test differences between sexes as well as differences within each sex, and paired $t$ tests to directly compare within each sex the effects of maternal treatment versus the control group.

progenitor cells in the NEP+mHYP, with female embryos exhibiting greater sensitivity to ethanol.

\section{Maternal ethanol administration stimulates radial glia cells in NEP and processes in MHYP more strongly in female than male embryos}

We next wanted to determine whether maternal ethanol stimulates $\mathrm{BLBP}^{+}$neuroprogenitor cells and whether this effect is sex-related. Using IF, we examined the effect of maternal administration of ethanol compared to Control and Untreated control groups on $\mathrm{BLBP}^{+}$neuroprogenitor cells separately in the NEP and mHYP of female and male embryos. The $\mathrm{BLBP}^{+}$radial glia cells were detected in the hypothalamic NEP and highly concentrated along the border of the third ventricle while very sparse in the mHYP. These cells have long, well-defined processes which project laterally through the mHYP in the direction of the LH. Maternal ethanol had strong stimulatory 
Table 4 Body weights of embryos and dams and the chow intake and litter size of dams

\begin{tabular}{llll}
\hline Ethanol & & & \\
& Untreated & Control & Ethanol \\
Body weight_E19 (g) & $6.670 \pm 0.39$ & $6.120 \pm 0.16$ & $6.310 \pm 0.19$ \\
Body weight_dams (g) & $295.5 \pm 8.5$ & $285.0 \pm 12.3$ & $282.1 \pm 10.3$ \\
Chow intake (kcal/day) & $71.90 \pm 2.9$ & $70.70 \pm 3.2$ & $65.40 \pm 3.4$ \\
Litter size & $11.70 \pm 1.0$ & $12.40 \pm 0.7$ & $12.70 \pm 0.6$ \\
CCL2 & & & \\
& Untreated & Control & CCL2 \\
Body weight—E19 (g) & $6.200 \pm 0.28$ & $6.000 \pm 0.17$ & $6.040 \pm 0.18$ \\
Body weight—dams (g) & $292.1 \pm 7.4$ & $277.3 \pm 5.0$ & $279.1 \pm 6.5$ \\
Chow intake (kcal/day) & $66.70 \pm 4.1$ & $68.40 \pm 3.2$ & $64.10 \pm 4.4$ \\
Litter size & $11.70 \pm 1.2$ & $12.40 \pm 0.7$ & $12.70 \pm 0.6$ \\
Ethanol + INCB & & & \\
& Control & Ethanol & Ethanol + INCB3344 \\
Body weight—E19 (g) & $6.290 \pm 0.23$ & $6.070 \pm 0.23$ & $6.160 \pm 0.13$ \\
Body weight—dams (g) & $280.3 \pm 8.7$ & $273.9 \pm 11.0$ & $282.7 \pm 9.1$ \\
Chow intake (kcal/day) & $75.30 \pm 4.7$ & $72.20 \pm 3.0$ & $69.50 \pm 2.7$ \\
Litter size & $11.30 \pm 1.0$ & $11.60 \pm 1.3$ & $11.00 \pm 1.2$
\end{tabular}

Data are mean \pm SEM. $n=7 /$ group, ${ }^{*} p<0.05$ versus control. Two-way ANOVA was used to compare means between groups and showed no significant effect of maternal administration of ethanol, CCL2 or CCR2 antagonist, INCB3344, on these measures

kcal/day kilocalories per day, $g$ grams, INCB3344 CCR2 antagonist

and sexually dimorphic effects on these cells and their processes. There was a significant main effect of ethanol treatment on the density of $\mathrm{BLBP}^{+}$cells in the $\operatorname{NEP}(F(2$, 36) $=38.54, p<0.001)$ and $\mathrm{BLBP}^{+}$processes in the mHYP $(F(2,36)=34.69, p<0.001)$, along with an effect of sex on $\mathrm{BLBP}^{+}$cells $(F(1,36)=16.10, p<0.001)$ and processes $(F(2,36)=34.69, p<0.001)$ and a sex $\times$ treatment interaction for $\mathrm{BLBP}^{+}$cells $(F(2,36)=5.18, p=0.011)$ and processes $(F(2,36)=9.61, p<0.001)$ (Fig. 3a), as illustrated in the photomicrographs (Fig. 3b). While there were no differences between respective control groups of females and males, ethanol-exposed females compared to ethanolexposed males had a significantly higher density of the $\mathrm{BLBP}^{+}$cells in the NEP $(p<0.001)$ and $\mathrm{BLBP}^{+}$processes in the mHYP $(p<0.001)$. Also, maternal ethanol had a significant, stimulatory effect in both sexes on the density of $\mathrm{BLBP}^{+}$cells in the NEP compared to the Control $(p<0.001$ for female and $p<0.001$ for male) and Untreated $(p<0.001$ for female and $p=0.003$ for male) groups and the density of $\mathrm{BLBP}^{+}$processes in the mHYP compared to the Control $(p<0.001$ for female and $p=0.013$ for male) and Untreated ( $p<$ 0.001 for female and $p=0.036$ for male) groups. However, the increase in density of $\mathrm{BLBP}^{+}$cells was significantly greater in females than males compared to the Control $(t(12)=3.058, p=0.010)$ and Untreated $(t(12)=5.0144, p=0.021)$ groups, similar to the increase in density of $\mathrm{BLBP}^{+}$processes compared to the Control $(t(12)=4.874, p<0.001)$ and Untreated $(t(12)=3.353, p=0.006)$ groups. Together, these results show that maternal ethanol administration at a moderate dose has a strong stimulatory effect on radial glia cells in the hypothalamic NEP and their processes in the mHYP, which are sexually dimorphic, consistently stronger in females than males.

\section{Maternal ethanol administration stimulates CCL2 and CCR2} mRNA in NEP and mHYP predominantly in female embryos Building on our previously published finding that CCL2 and CCR2 expression is increased in the LH of embryos exposed to ethanol, we next determined whether maternal ethanol alters their expression in the NEP of embryos and whether this effect is similarly sex-related. Using qRT-PCR, we examined the effect of maternal ethanol administration compared to Control and Untreated control groups on gene expression of this chemokine and its receptor and found a significant main effect of ethanol treatment on CCL2 $(F(2,36)=15.88, p$ $<0.001)$ and $\operatorname{CCR} 2(F(2,36)=22.23, p<0.001)$, along with an effect of sex on CCL2 $(F(1,36)=9.78, p=$ $0.003)$ and CCR2 $(F(2,36)=17.99, p<0.001)$ and a significant interaction between sex and ethanol treatment for CCL2 $(F(2,36)=4.73, p=0.015)$ and CCR2 $(F(2,36)$ $=4.22, p=0.023)$ (Table 5). While again there were no differences between respective control groups of females and males, ethanol-exposed females exhibited a greater expression of CCL2 $(p<0.001)$ and CCR2 $(p=0.002)$ compared to males. Also, maternal ethanol administration compared to control groups significantly increased CCL2 mRNA levels in female embryos $(p<0.001$ for Control and $p<0.001$ for Untreated) but had no effect in male embryos $(p=0.067$ for Control and $p=0.298$ for Untreated). In addition, while ethanol significantly increased CCR2 mRNA levels in both sexes compared to their Control $(p<0.001$ for female and $p=0.037$ for male) and Untreated ( $p<0.001$ for female and $p=0.016$ for male) groups, the ethanol-induced increase in CCR2 mRNA in females was significantly greater than in males $(t(12)=3.738, p=0.003)$ (Table 5). Together, these results demonstrate that maternal ethanol increases the expression of CCL2 in female but not in male embryos and the expression of CCR2 in the females greater than the males.

\section{Maternal ethanol administration stimulates the density of CCL2 cells in NEP and processes in MHYP predominantly} in female embryos

The purpose of this experiment was to determine whether, in addition to stimulating the gene expression of CCL2, maternal ethanol exposure also alters the density of CCL2 ${ }^{+}$cells in E19 embryos. Using IF, we detected in E19 embryos a high concentration of CCL2 ${ }^{+}$cells in the NEP along the border of the third ventricle, with very few 
a
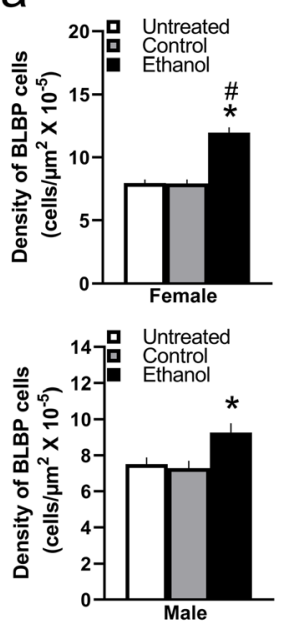
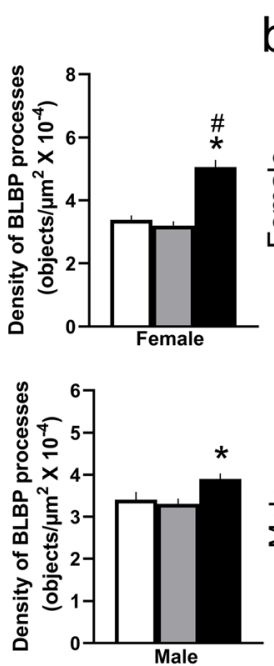

b Control
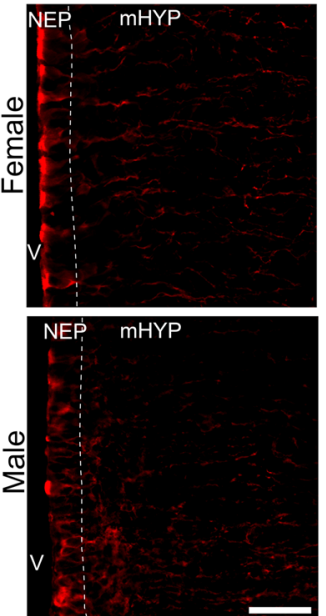

Ethanol
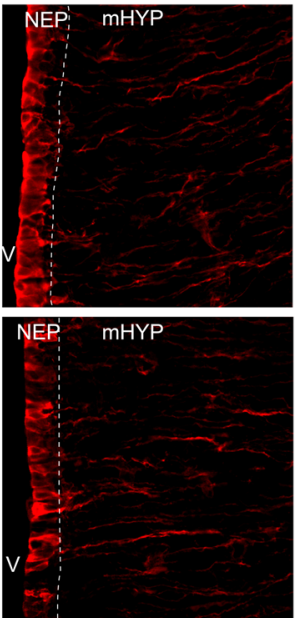

Fig. 3 Effects of ethanol on the density of BLBP ${ }^{+}$radial glia in NEP and mHYP. Maternal ethanol administration group (2 g/kg/day, E10-E15) was compared to Untreated and isocaloric Control groups of E19 embryos, and the density of cells and processes was examined using single-labeled immunofluorescence histochemistry. a Ethanol significantly increased the density of $\mathrm{BLBP}^{+}$radial glia cells in NEP and of BLBP ${ }^{+}$processes in mHYP of both female and male embryos, with females showing a significantly greater effect. $\mathbf{b}$ These effects in ethanol-exposed compared to control embryos are illustrated in representative immunostaining images $(\times 20)$ of single-labeled BLBP ${ }^{+}$cells in NEP and BLBP ${ }^{+}$processes in mHYP of female and male embryos. Data are mean \pm SEM. ( $n=7 /$ group/sex, ${ }^{*} p<0.05$ versus control group, ${ }^{\#} p<0.05$ versus males). Two-way ANOVA was used to compare means between groups, simple main effect analyses to test the differences between sexes as well as differences within each sex, and paired $t$ tests to directly compare the effects within each sex of maternal treatment vs control groups. BLBP, brain lipid-binding protein; mHYP, medial hypothalamus; NEP, neuroepithelium; V, third ventricle. Scale bars, $200 \mu \mathrm{m}$

evident in the mHYP, and found these CCL2 ${ }^{+}$cells to be far denser in the NEP than the LH [12], with some having a distinct shape of short, lightly stained processes projecting laterally into the mHYP. Maternal ethanol administration had sexually dimorphic, stimulatory effects on both the $\mathrm{CCL}_{2}{ }^{+}$cells and processes (Fig. 4a), as illustrated in the photomicrographs (Fig. 4b). There was a significant main effect of ethanol treatment on the density of CCL2 ${ }^{+}$cells in the NEP $(F(2,36)=18.04, p<0.001)$ and of CCL2 ${ }^{+}$processes in the $\operatorname{mHYP}(F(2,36)=23.30, p<0.001)$, along with an effect of sex on CCL2 ${ }^{+}$cells $(F(1,36)=28.50, p<0.001)$ and processes $(F(1,36)=39.46, p<0.001)$ as well as a significant sex $\times$ treatment interaction on CCL2 ${ }^{+}$cells $(F(2$, $36)=5.84, p<0.001)$ and processes $(F(2,36)=10.62, p<$ $0.001)$. While there were no differences between respective control groups of females and males, ethanol-exposed females had a significantly greater density of CCL2 $2^{+}$cells in the NEP $(p<0.001)$ and CCL2 $2^{+}$processes $(p<0.001)$ in the mHYP. Ethanol treatment significantly increased in females the density of CCL $2^{+}$cells in the NEP compared to the Control $(p<0.001)$ and Untreated $(p<0.001)$ groups, while having no effect on CCL2 ${ }^{+}$cells in the NEP of male embryos compared to the Control $(p=0.732)$ and Untreated $(p=0.080)$ groups. Similarly, ethanol also increased in females the density of CCL2 $2^{+}$processes in the mHYP compared to the Control $(p<0.001)$ and Untreated $(p<$ 0.001 ) groups, while having no effect on the processes in the mHYP of male embryos compared to the Control ( $p=$ $0.251)$ and Untreated $(p=0.108)$ groups. Together, these results demonstrate a stimulatory effect of maternal ethanol on $\mathrm{CCL}_{2}{ }^{+}$cells and processes in females but not males, similar to that shown for CCL2 mRNA and consistent with the stimulatory effect of ethanol on CCR2 mRNA that is stronger in females than males.

Table 5 Effects of maternal ethanol administration on mRNA of CCL2 and CCR2 in NEP+mHYP area in E19 embryos

\begin{tabular}{|c|c|c|c|c|c|c|}
\hline \multirow{2}{*}{$\begin{array}{l}\text { mRNA } \\
\text { Expression }\end{array}$} & \multicolumn{3}{|l|}{ Female } & \multicolumn{3}{|l|}{ Male } \\
\hline & Untreated & Control & Ethanol & Untreated & Control & Ethanol \\
\hline $\mathrm{CCL} 2$ & $1.2 \mathrm{E}-3 \pm 5.7 \mathrm{E}-5$ & $1.2 \mathrm{E}-3 \pm 5.1 \mathrm{E}-5$ & $1.9 \mathrm{E}-3 \pm 4.0 \mathrm{E}-5^{* \#}$ & $1.3 \mathrm{E}-3 \pm 6.1 \mathrm{E}-5$ & $1.3 \mathrm{E}-3 \pm 5.5 \mathrm{E}-5$ & $1.4 \mathrm{E}-3 \pm 5.7 \mathrm{E}-5$ \\
\hline CCR2 & $4.7 \mathrm{E}-3 \pm 2.3 \mathrm{E}-4$ & $4.5 E-3 \pm 2.1 E-4$ & $6.7 \mathrm{E}-3 \pm 3.1 \mathrm{E}-4^{* \#}$ & $4.6 \mathrm{E}-3 \pm 4.0 \mathrm{E}-4$ & $4.2 \mathrm{E}-3 \pm 2.3 \mathrm{E}-4$ & $5.0 E-3 \pm 2.1 E-4^{*}$ \\
\hline
\end{tabular}

Effect of maternal administration of ethanol ( $2 \mathrm{~g} / \mathrm{kg} /$ day, E10-E15) on mRNA levels of CCL2 and CCR2 was measured using qRT-PCR. Data are expressed as an averaged ratio (target gene expression/house-keeping gene expression) in each group and presented as mean \pm SEM ( $n=7 /$ group/sex, ${ }^{*} p<0.05$ versus Control). Two-way ANOVA was used to compare means between groups, simple main effect analyses to test differences between sexes as well as differences within each sex, and paired $t$ tests to directly compare within each sex the effects of maternal treatment vs control groups NEP hypothalamic neuroepithelium, $m H Y P$ medial hypothalamus, $q R T-P C R$ real-time quantitative PCR $\# p<0.05$ vs males 


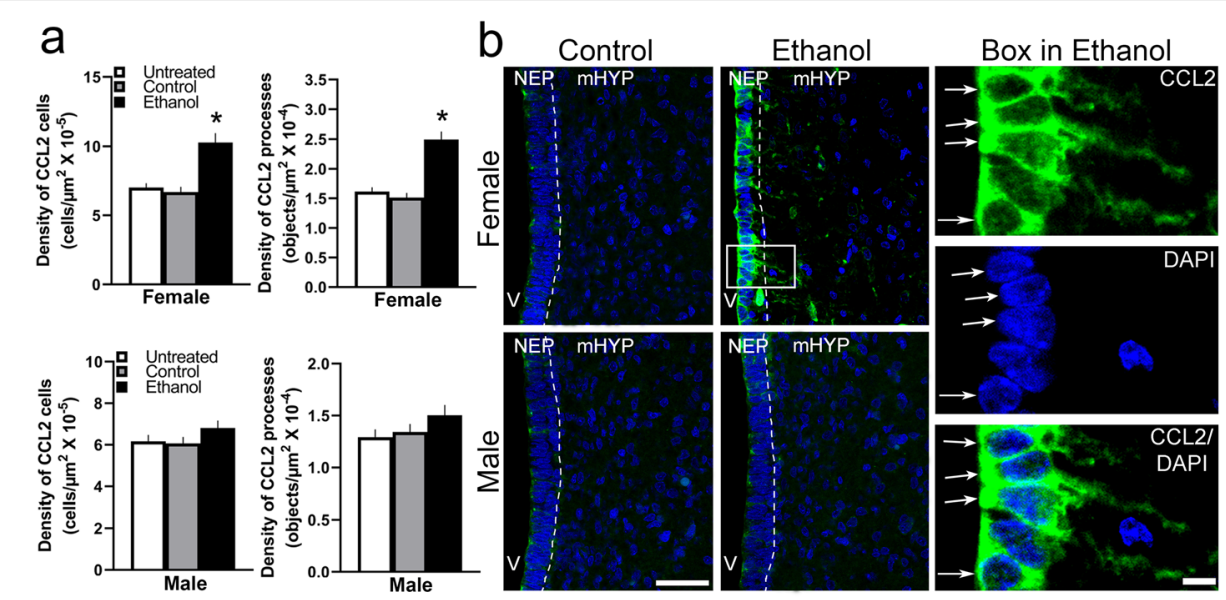

Fig. 4 Stimulatory effects of ethanol on expression and density of CCL2 ${ }^{+}$cells in NEP and processes in mHYP. Maternal ethanol administration group (2 g/kg/day, E10-E15) was compared to Untreated and isocaloric Control groups of embryos at E19, and the density of cells and processes was examined using single-labeled immunofluorescence histochemistry. a Ethanol significantly increased the density of CCL2 ${ }^{+}$cells in NEP and $\mathrm{CCL}^{+}$processes in $\mathrm{mHYP}$ of female embryos, but it had no effect in male embryos. $\mathbf{b}$ These effects in ethanol-exposed female embryos are illustrated in representative immunostaining images $(\times 20)$ of double-labeled CCL2 ${ }^{+}$cells in NEP and their CCL2 ${ }^{+}$processes in mHYP with DAPI, with cells and processes in box illustrated to the right in $\times 40$ images and both the CCL2 ${ }^{+}$cells and processes in male embryos $(\times 20$ images) exhibiting no significant change. Data are mean \pm SEM. ( $n=7 /$ group $/$ sex, ${ }^{*} p<0.05$ versus control group, ${ }^{\#} p<0.05$ versus males). Two-way ANOVA was used to compare means between groups and simple main effect analyses to test differences between sexes as well as differences within each sex. NEP, neuroepithelium; mHYP, medial hypothalamus; $V$, third ventricle. Scale bars, $200 \mu \mathrm{m}$

\section{Maternal administration of CCL2 stimulates $\mathrm{BLBP}^{+}$and} $\mathrm{CCL}^{+}$cells in the NEP and processes in the mHYP

The purpose of this experiment was to determine whether CCL2 administration, similar to ethanol as shown above, also stimulates radial glia in the NEP and mHYP along with endogenous CCL2/CCR2 signaling.
Using IF, we tested female E19 embryos from dams that were either untreated (Untreated) or given daily injections (s.c., E10-E15) of CCL2 at $4 \mu \mathrm{g} / \mathrm{kg} /$ day (CCL2) compared to sterile water vehicle (Control). There was a significant main effect of maternal CCL2 injection on the density of $\operatorname{BLBP}^{+}(F(2,20)=23.41, p<0.001)$ and
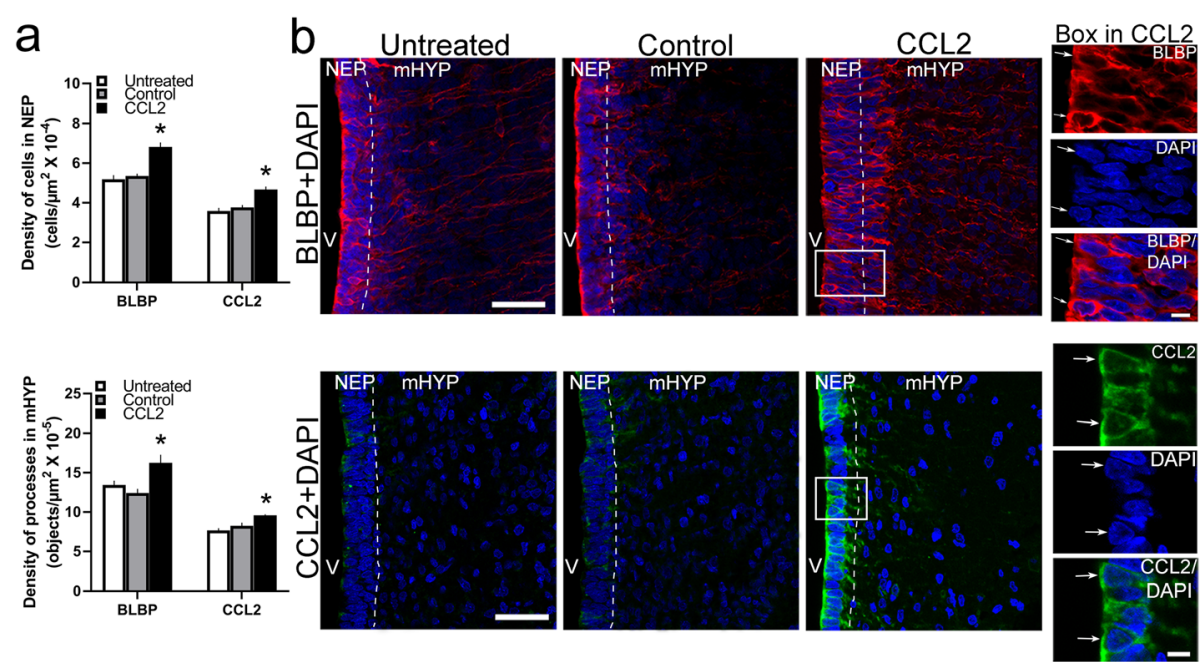

Fig. 5 Stimulatory effects of CCL2 injection on $\mathrm{BLBP}^{+}$and $\mathrm{CCL}^{+}$cells and processes in NEP and $\mathrm{mHYP}$. Maternal administration of CCL2 $(4 \mu \mathrm{\mu g} / \mathrm{kg} /$ day, E10-E15) group was compared to Untreated and vehicle Control groups of female embryos at E19, and the density of cells and processes was analyzed using single-labeled immunofluorescence histochemistry. a CCL2 administration compared to control groups significantly increased the density of $\mathrm{BLBP}^{+}$and $\mathrm{CCL} 2^{+}$cells in NEP and processes in $\mathrm{mHYP}$. $\mathbf{b}$ These effects of ethanol compared to isocaloric Control group are illustrated in representative immunostaining images of double-labeled $\mathrm{BLBP}^{+}$cells and processes (red) and CCL2 ${ }^{+}$cells and processes (green) with the nuclear stain DAPI (blue). Data are mean \pm SEM. ( $n=7 /$ group, ${ }^{*} p<0.05$ versus control group). One-way ANOVA was used to compare group means followed by SDS post hoc test. mHYP, medial hypothalamus; NEP, neuroepithelium; $V$, third ventricle. Scale bar, $100 \mu \mathrm{m}$ 
$\operatorname{CCL}^{+}(F(2,20)=15.59, p<0.001)$ cells in the NEP and of $\operatorname{BLBP}^{+}(F(2,20)=7.525, p=0.004)$ and $\mathrm{CCL}^{+}(F(2$, $20)=11.857, p<0.001$ ) processes in the mHYP (Fig. 5a), as illustrated in the photomicrographs (Fig. 5b). Maternal CCL2 significantly increased in the NEP the density of $\mathrm{BLBP}^{+}$cells compared to Control $(p<0.001)$ and Untreated $(p<0.001)$ groups and of CCL2 ${ }^{+}$cells compared to Control $(p<0.001)$ and Untreated $(p<0.001)$ groups. It also increased the density of $\mathrm{BLBP}^{+}$processes compared to Control $(p<0.001)$ and Untreated $(p=0.013)$ groups and of CCL2 ${ }^{+}$processes compared to Control $(p=0.004)$ and Untreated $(p<0.001)$ groups. Examination of the effect of maternal CCL2 on body weights revealed no significant main effect in the dams at $\operatorname{E19}(F(2,18)=$ $1.921, p=0.175)$ or the E19 embryos $(F(2,18)=$ $0.251 p=0.781)$ and also no effect on dam's chow intake $(F(2,18)=0.309, p=0.738)$ and litter size $(F(2,18)=0.405, p=0.673)$ (Table 4$)$. These results confirm that maternal administration of CCL2 mimics the effects of maternal ethanol, stimulating the cells and processes of both radial glia and CCL2 in the hypothalamic NEP and mHYP.

\section{Maternal administration of CCR2 antagonist blocks ethanol's stimulatory effects on BLBP and CCL2 mRNA}

With CCR2 shown to be involved in the stimulatory effect of maternal ethanol administration on CCL2 neurons in the LH $[11,12]$, we next tested the effect of a blockade of this receptor with maternal administration of the CCR2 receptor antagonist INCB3344 during the period of ethanol exposure on the radial glia and CCL2/ CCR2 system in the NEP and mHYP. Using qRT-PCR, we examined female embryos at E19 in the following four groups: Isocaloric Control + Vehicle (Control); Ethanol + Vehicle (Ethanol); Ethanol + INCB3344; and Control + INCB3344. There was a significant main effect of treatment on mRNA levels of $\operatorname{BLBP}(F(3,27)=9.051$, $p<0.001)$ and $\operatorname{CCL} 2(F(3,27)=14.795, p<0.001)$ as well as CCR2 $(F(3,27)=6.690, p=0.002)$ in the NEP+ mHYP area (Table 6). Maternal ethanol compared to Control significantly increased the expression of BLBP $(+43 \%, p<0.001)$ and CCL2 $(+57 \%, p<0.001)$ as well as of CCR2 $(+49 \%, p=0.002)$, and these effects were blocked by maternal administration of the CCR2 antagonist, causing a decrease in mRNA expression of $\operatorname{BLBP}(p<0.001), \operatorname{CCL} 2(p<0.001)$, and CCR2 $(p=$ $0.006)$ to the same levels as those in the Control group ( $p=0.336, p=0.641$, and $p=0.483$, respectively). The antagonist alone was found to have no effect of its own on these measures, with no differences evident between the Control + INCB3344 and the Control groups in their expression of BLBP $(p=0.956)$, CCL2 $(p=0.912)$, and CCR2 $(p=0.513)$. Consistent with our previous findings [15], maternal administration of CCR2 antagonist had no significant main effect on the body weight of dams at E19 $(F(3,24)=0.315, p=0.906)$ or their E19 embryos $(F(3,24)=0.184, p=0.906)$ and also no effect on the dam's chow intake $(F(3,24)=0.372, p=0.774)$ and litter size $(F(3,24)=0.405, p=0.750)$ (Table 4). These findings support the involvement of the endogenous CCR2 receptor in mediating ethanol's stimulatory effect on the radial glia and CCL2/CCR2 system in the NEP and mHYP.

\section{Maternal administration of CCR2 antagonist blocks ethanol's stimulatory effects on BLBP and CCL2 cells and processes}

Building on our finding from the above experiment that CCR2 antagonist blocks ethanol-induced effect on BLBP and CCL2 mRNA, we wanted to determine here whether this effect extends to $\mathrm{BLBP}^{+}$and $\mathrm{CCL} 2^{+}$cells and their processes. Using single-label IF, we examined female embryos at E19 from dams in the following four groups: Isocaloric Control + Vehicle (Control); Ethanol + Vehicle (Ethanol); Ethanol + INCB3344; and Control + INCB3344. We found a significant main effect of treatment on the density of $\operatorname{BLBP}^{+}(F(3,27)=10.228, p<$ $0.001)$ and $\operatorname{CCL} 2^{+}(F(3,27)=5.572, p=0.005)$ cells and of $\mathrm{BLBP}^{+}(F(3,27)=9.481, p<0.001)$ and $\mathrm{CCL}^{+}(F(3$, $27)=18.543, p<0.001$ ) processes (Fig. $6 \mathrm{a}$ ), as illustrated in the photomicrographs (Fig. 6b). Ethanol compared to Control group caused a significant increase in the density of $\mathrm{BLBP}^{+}(+36 \%, p<0.001)$ and $\mathrm{CCL}^{+}(+53 \%, p<$ $0.001)$ cells in the NEP and of $\mathrm{BLBP}^{+}(+31 \%, p<0.001)$ and CCL2 $2^{+}(+67 \%, p<0.001)$ processes in the mHYP. These effects were reversed by INCB3344 treatment, causing a significant decrease in the Ethanol + INCB3344 compared to Ethanol group in the density of

Table 6 Effects of ethanol and CCR2 antagonist, INCB3344, on BLBP, CCL2, and CCR2 mRNA in NEP+mHYP area

\begin{tabular}{lllll}
\hline mRNA expression & Control & Ethanol & Ethanol + INCB3344 & Control + INCB3344 \\
\hline BLBP & $2.3 \mathrm{E}-1 \pm 9.4 \mathrm{E}-3$ & $3.3 \mathrm{E}-1 \pm 2.2 \mathrm{E}-2^{*}$ & $2.5 \mathrm{E}-1 \pm 1.9 \mathrm{E}-2$ & $2.3 \mathrm{E}-1 \pm 6.4 \mathrm{E}-3$ \\
CCL2 & $1.3 \mathrm{E}-3 \pm 4.9 \mathrm{E}-5$ & $2.0 \mathrm{E}-3 \pm 1.5 \mathrm{E}-4^{*}$ & $1.4 \mathrm{E}-3 \pm 6.9 \mathrm{E}-5$ & $1.2 \mathrm{E}-3 \pm 5.2 \mathrm{E}-5$ \\
CCR2 & $4.5 \mathrm{E}-1 \pm 3.4 \mathrm{E}-3$ & $6.7 \mathrm{E}-3 \pm 5.4 \mathrm{E}-4^{*}$ & $4.8 \mathrm{E}-3 \pm 4.1 \mathrm{E}-4$ & $4.1 \mathrm{E}-3 \pm 4.8 \mathrm{E}-4$ \\
\hline
\end{tabular}

Maternal ethanol administration group (2 g/kg/day, E10-E15) with and without INCB3344 treatment (1 mg/kg/day, i.p.) was compared to Untreated and isocaloric Control groups of embryos at E19. Data are expressed as an averaged ratio (target gene expression/house-keeping gene expression) in each group and presented as mean \pm SEM ( $n=7 /$ group, ${ }^{*} p<0.05$ versus Control, Ethanol + INCB3344, and Control + INCB3344 groups). Difference between groups was analyzed using oneway ANOVA followed by SDS post hoc test

$B L B P$ brain lipid-binding protein, NEP neuroepithelium 

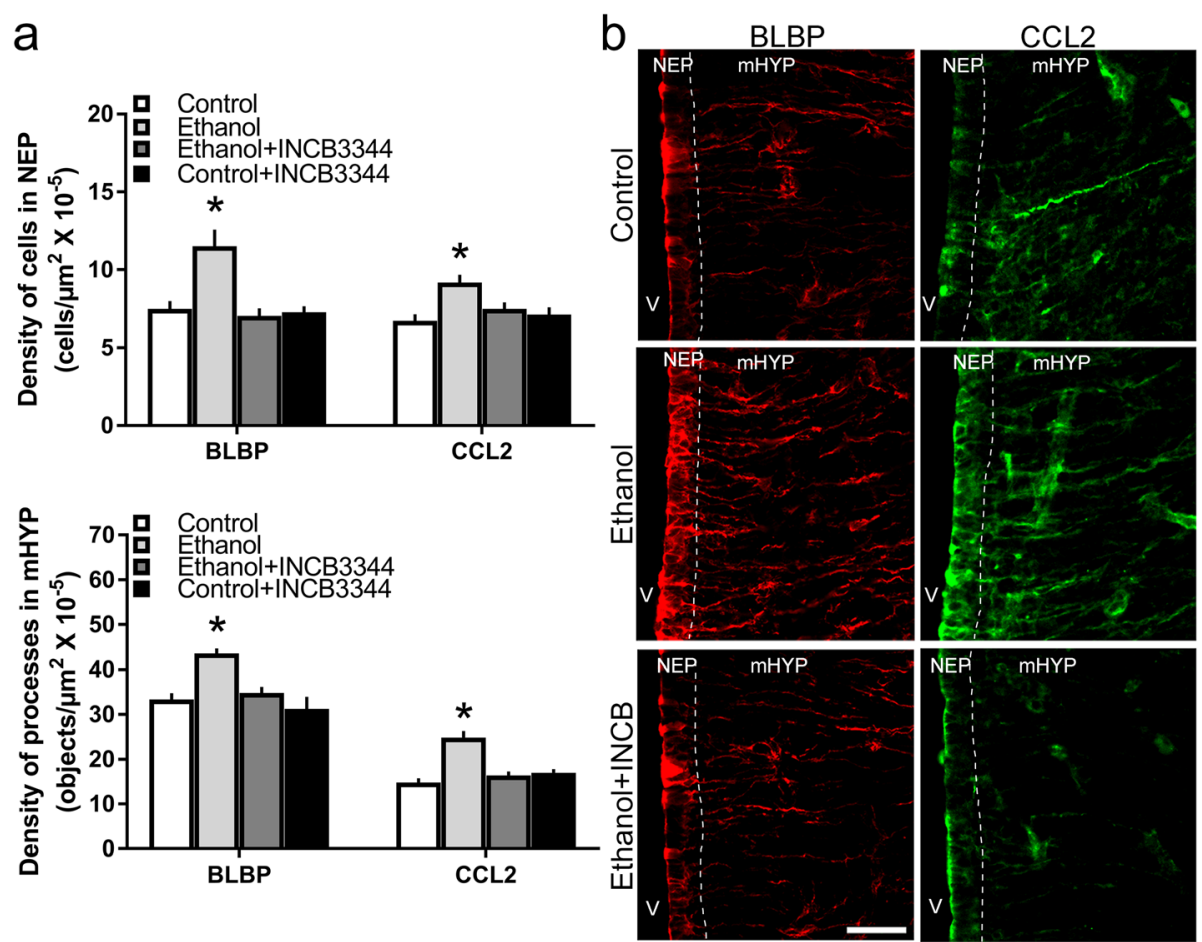

Fig. 6 Impact of CCR2 receptor antagonist on ethanol's effects on BLBP ${ }^{+}$and CCL2 ${ }^{+}$cells and processes. Maternal injection of CCR2 receptor antagonist, INCB3344 (1 mg/kg/day, i.p.), was performed during the period of maternal ethanol administration (2 g/kg/day, E10-E15) and was compared to the Ethanol, Control, and Control + INCB3344 groups of E19 female embryos. a Analysis using single-labeled immunofluorescence histochemistry showed that Ethanol treatment compared to Control group significantly increased the density of BLBP ${ }^{+}$and CCL2 $2^{+}$cells in NEP and processes in mHYP and the INCB3344 treatment during ethanol exposure blocked this effect, causing a significant decrease in the Ethanol + INCB3344 group compared to Ethanol group in cells and processes reduced to the same levels as those in the Control group. $\mathbf{b}$ These effects in the embryo are illustrated in representative images $(\times 20)$ of $\mathrm{BLBP}^{+}$and $\mathrm{CCL}^{+}$single-labeled cells and processes in the Control, Ethanol, and Ethanol + INCB3344 embryos. Data are mean \pm SEM ( $n=7 /$ group, ${ }^{*} p<0.05$ versus the Control, Ethanol + INCB3344, and Control + INCB3344 groups). Differences between groups were analyzed using one-way ANOVA followed by SDS post hoc test. BLBP, brain lipid-binding protein; mHYP, medial hypothalamus; NEP, neuroepithelium; V, third ventricle. Scale bar, $100 \mu \mathrm{m}$

$\mathrm{BLBP}^{+}$cells $(p=0.004)$ and processes $(p=0.002)$ and $\mathrm{CCL}^{+}$cells $(p=0.006)$ and processes $(p<0.001)$ that were reduced to the same levels as those in the Control group for $\mathrm{BLBP}^{+}$cells $(p=0.471)$ and processes $(p=0.639)$ and CCL2 ${ }^{+}$cells $(p=0.561)$ and processes $(p=0.310)$. There were no differences between the Control + INCB3344 group and the Control group in the measures of $\operatorname{BLBP}^{+}(p=0.820)$ and CCL2 $2^{+}(p=0.538)$ cells and $\operatorname{BLBP}^{+}(p=0.406)$ and $\operatorname{CCL}^{+}(p=0.164)$ processes. These results demonstrate the importance of CCR2 in mediating ethanol's stimulatory effects on the cells and processes of radial glia in the NEP and MHYP.

\section{Maternal ethanol stimulates co-labeling of CCL2 in radial glia cells and neurons}

Building on our published evidence that maternal ethanol stimulates CCL2 in the LH predominantly in neurons but not in microglia or astrocytes [12], we wanted in this experiment to determine the effect of maternal CCL2 on these neurons and radial glia in the NEP and mHYP. Using BLBP as the marker of radial glia, NeuN to label neurons, and Iba-1 to label microglia, we employed double-labeling IF to examine in female E19 embryos the co-labeling of CCL2 with BLBP, NeuN, and Iba-1. Maternal ethanol exposure stimulated all three cell types, radial glia, neurons, and microglia in the NEP and mHYP (Table 7). Confirming the above results, analyses of single-labeled cells and processes showed that maternal administration of ethanol compared to the Control group significantly increased the density of $\mathrm{CCL}_{2}{ }^{+}$cells in the NEP $(p=0.014)$ and processes in the $\operatorname{mHYP}(p<0.001)$ and of $\mathrm{BLBP}^{+}$cells in the NEP $(p=$ $0.002)$ and processes in the mHYP $(p=0.016)$. They further revealed a stimulatory effect of ethanol on the density of $\mathrm{NeuN}^{+}$neurons, which were most concentrated along the periventricular region of the NEP $(p=0.010)$ while scattered throughout the mHYP $(p=0.026)$, and also of Iba- $1^{+}$microglia, which were detected along the lateral border of the NEP $(p=0.009)$ as well as scattered in the mHYP $(p<0.001)$ (Table 7).

Analysis of the double-labeled cells and processes show CCL2 to colocalize with BLBP in radial glia and 
Table 7 Effects of ethanol on density of cells or processes that label CCL2, BLBP, NeuN, or lba-1 in NEP and mHYP

\begin{tabular}{llll}
\hline Labeled cells/processes & Location & Control $\left(\right.$ cells, objects $\left./ \mu m^{2}\right)$ & Ethanol $\left(\right.$ cells, objects/ $\left.\mu m^{2}\right)$ \\
\hline $\mathrm{CCL2}^{+}$ & NEP & $6.30 \mathrm{E}-5 \pm 2.67 \mathrm{E}-6$ & $7.50 \mathrm{E}-5 \pm 2.07 \mathrm{E}-6^{*}$ \\
& mHYP & $9.90 \mathrm{E}-5 \pm 7.30 \mathrm{E}-6$ & $1.70 \mathrm{E}-4 \pm 1.46 \mathrm{E}-5^{*}$ \\
$\mathrm{BLBP}^{+}$ & NEP & $1.51 \mathrm{E}-4 \pm 4.62 \mathrm{E}-6$ & $1.83 \mathrm{E}-4 \pm 5.67 \mathrm{E}-6^{*}$ \\
& mHYP & $1.59 \mathrm{E}-4 \pm 1.32 \mathrm{E}-5$ & $2.31 \mathrm{E}-4 \pm 2.13 \mathrm{E}-5^{*}$ \\
$\mathrm{NeuN}^{+}$ & NEP & $5.75 \mathrm{E}-5 \pm 2.77 \mathrm{E}-6$ & $7.92 \mathrm{E}-5 \pm 7.24 \mathrm{E}-6^{*}$ \\
& mHYP & $4.28 \mathrm{E}-5 \pm 2.68 \mathrm{E}-6$ & $5.17 \mathrm{E}-5 \pm 2.64 \mathrm{E}-6^{*}$ \\
${\mathrm{Iba}-1^{+}}^{*}$ & NEP & $3.79 \mathrm{E}-5 \pm 1.84 \mathrm{E}-6$ & $4.73 \mathrm{E}-5 \pm 1.79 \mathrm{E}-6^{*}$ \\
& mHYP & $4.47 \mathrm{E}-5 \pm 2.14 \mathrm{E}-6$ & $6.06 \mathrm{E}-5 \pm 4.27 \mathrm{E}-6^{*}$
\end{tabular}

Maternal administration of ethanol ( $2 \mathrm{~g} / \mathrm{kg} /$ day, E10-E15) was compared to an isocaloric maltose-dextrin control solution (Control) group in the NEP and mHYP areas of female E19 embryos, measured using single-labeling IF. Data are mean \pm SEM, $n=6 /$ group, ${ }^{*} p<0.05$ versus Control. The difference between groups was analyzed using Student $t$ test

BLBP brain lipid-binding protein, CCL2 C-C motif ligand 2, lba-1 microglial marker, mHYP medial hypothalamus, NEP hypothalamic neuroepithelium, NeuN neuronal marker

$\mathrm{NeuN}$ in neurons and maternal ethanol to stimulate their colocalization (Fig. 7a), as illustrated in the photomicrographs (Fig. 7b), but fail to reveal any colocalization of CCL2 with Iba-1 in microglia under any condition. Ethanol compared to Control significantly increased the percentage of double-labeled CCL2 $2^{+} / \mathrm{BLBP}^{+}$cells in the NEP relative to single-labeled $\mathrm{BLBP}^{+}(t(10)=-32.05, p<0.001)$ and $\mathrm{CCL}^{+}(t(10)=-10.21, p<0.001)$ cells and of doublelabeled $\mathrm{CCL}^{+} / \mathrm{BLBP}^{+}$processes in the mHYP relative to single-labeled $\mathrm{BLBP}^{+}(t(10)=-10.374, p<0.001)$ and $\operatorname{CCL}^{+}(t(10)=-8.359, p<0.001)$ processes. These effects on double-labeled radial glia, evident in the $\times 20$ photomicrographs of Ethanol compared to Control groups, are more clearly illustrated in the $\times 40$ images to the right with arrowheads identifying the radial glia cells and processes (Fig. 7b). In addition, as described in the LH $[11,12]$. Ethanol compared to Control significantly increased the percentage of double-labeled $\mathrm{CCL} 2^{+} / \mathrm{NeuN}^{+}$neurons in the NEP relative to single-labeled $\mathrm{NeuN}^{+}$neurons $(t(10)=-$ 32.046, $p<0.001)$ and CCL2 ${ }^{+}$cells $(t(10)=-10.220, p<$ 0.001 ), and these double-labeled neurons were concentrated along the periventricular border of the NEP while very sparse in the mHYP, as illustrated in the $\times 20$ photomicrographs and identified by arrowheads in $\times 40$ images to the right (Fig. 7b). This is in contrast to Iba- $1^{+}$microglia, which while stimulated by ethanol showed no doublelabeling with CCL2. This analysis of CCL2 ${ }^{+}$cells in the hypothalamic NEP and mHYP demonstrates that, while

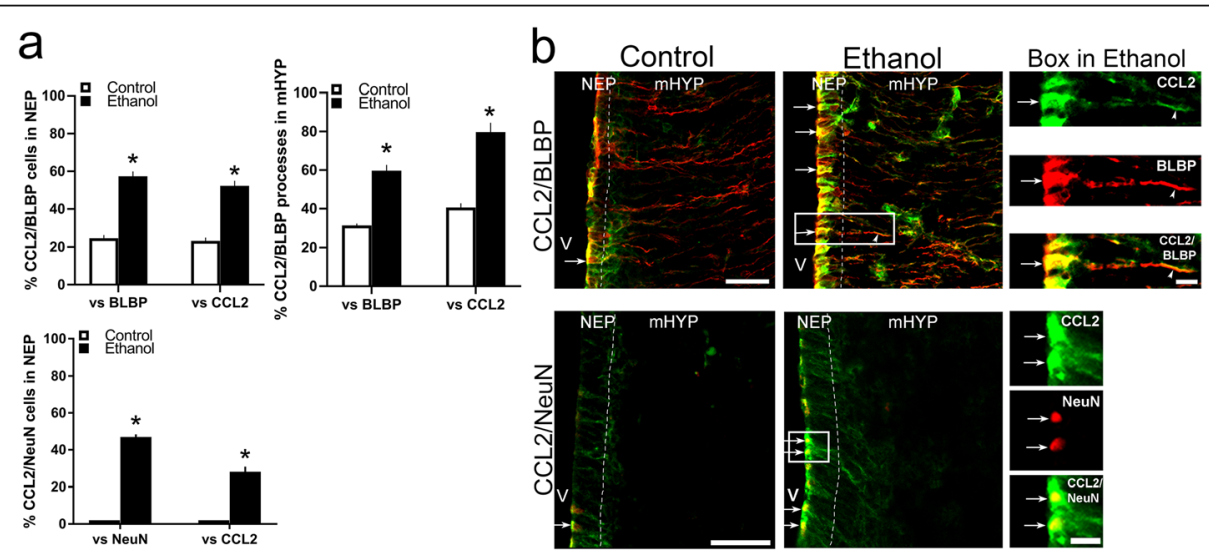

Fig. 7 Stimulatory effects of ethanol on CCL2 in radial glia and neurons. Maternal ethanol administration (2 g/kg/day, E10-E15) was compared to isocaloric Control group with measurements of radial glia, neurons, and microglia in E19 female embryos. a Ethanol compared to Control group significantly increased the percentage of double-labeled $\mathrm{CCL2}{ }^{+} / \mathrm{BLBP}^{+}$radial glia cells relative to single-labeled $\mathrm{BLBP}^{+}$or $\mathrm{CCL2}{ }^{+}$cells in $\mathrm{NEP}$ and double-labeled $\mathrm{CCL2} 2^{+} / \mathrm{BLBP}^{+}$radial glia processes relative to single-labeled $\mathrm{BLBP}^{+}$and $\mathrm{CCL2}{ }^{+}$processes in $\mathrm{mHYP}$. It also increased the percentage of double-labeled $\mathrm{CCL2}^{+} / \mathrm{NeuN}^{+}$neurons relative to single-labeled $\mathrm{NeuN}^{+}$neurons and $\mathrm{CCL}^{+}$cells in NEP, with double-labeled $\mathrm{CCL2}^{+} / \mathrm{NeuNN}^{+}$ neurons very sparse with no processes in the mHYP. $\mathbf{b}$ This effect of ethanol on double-labeled $\mathrm{CCL2}^{+} / \mathrm{BLBP}^{+}$cells and processes and $\mathrm{CCL2} 2^{+}$/ $\mathrm{NeuN}^{+}$neurons is illustrated in $\times 20$ images, with those in the box enlarged to the right $(\times 40)$ and showing (white arrows) the single-labeled $\mathrm{CCL2}^{+}$(green) and BLBP${ }^{+}$or $\mathrm{NeuN}^{+}$(red) cells and processes (white arrowheads) and the double-labeled CCL2 ${ }^{+} / \mathrm{BLBP}^{+}$cells and processes and $\mathrm{CCL}^{+} / \mathrm{NeuN}^{+}$cells (yellow). Data are mean $\pm \mathrm{SEM}$. ( $n=6 /$ group, ${ }^{*} p<0.05$ versus control group). Differences between groups were analyzed using one-way ANOVA followed by SDS post hoc test. BLBP, brain lipid-binding protein; mHYP, medial hypothalamus; NEP, neuroepithelium; $V$, third ventricle. Scale bars, $100 \mu \mathrm{m}$ 
few of the radial glia, neurons, and microglia contain CCL2 under control conditions, ethanol exposure stimulates all three cell types in the NEP and MHYP and increases the colocalization of CCL2 in 60\% of the radial glia and neurons while producing no colocalization in the microglia.

\section{Maternal ethanol increases $\mathrm{MCH}$-expressing neurons in the NEP and mHYP of female more than male embryos}

This experiment investigated whether ethanol's stimulatory effects on these CCL2 cells in the NEP are related to its effects on $\mathrm{MCH}$ neurons in the $\mathrm{LH}$ that colocalize CCL2 and CCR2 [11, 12, 15]. Embryos at E19 from two separate sets of dams were either untreated (Untreated) or received daily intraoral administration (from E10 to E15) of either $2 \mathrm{~g} / \mathrm{kg} /$ day of ethanol (Ethanol) or an isocaloric maltose-dextrin control solution (Control) were examined. Measurements of $\mathrm{MCH}$ expression in the $\mathrm{NEP}+\mathrm{mHYP}$ area of female and male embryos from the first set of dams revealed a significant increase in mRNA levels using qRT-PCR, albeit at much lower levels than found in the LH [12]. There was a significant main effect of ethanol treatment on $\mathrm{MCH}$ mRNA $(F(2,36)=29.913$, $p<0.001)$, in addition to an effect of $\operatorname{sex}(F(1,36)=$ 9.933, $p=0.003)$ and a sex $\times$ ethanol treatment interaction $(F(2,36)=5.018, p=0.012)$ (Fig. 8a). While there were no differences between respective control groups of females and males, the ethanol-exposed females exhibited a significantly greater expression of $\mathrm{MCH}$ than the males $(p<0.001)$. Further, while ethanol significantly increased $\mathrm{MCH}$ mRNA levels in both sexes compared to their Control $(p<0.001$ for female and $p=0.014$ for male) and Untreated ( $p<0.001$ for female and $p=0.005$ for male) groups, direct comparisons between females and males showed this effect of ethanol on $\mathrm{MCH}$ expression to be significantly greater in female than male embryos compared to the Control $(t(12)=2.802, p=0.016)$ and Untreated $(t(12)=4.152, p<0.001)$ groups (Fig. 8a). Analysis of these $\mathrm{MCH}^{+}$neurons using DIG-ISH in the Ethanol compared to Control female embryos from the second set of dams revealed a significant increase in their density in the NEP $(t(10)=-9.76, p<0.001)$ and $\operatorname{mHYP}(t(10)=-2.69, p=0.023)$ (Fig. 8a), as illustrated in the photomicrographs (Fig. 8b). A few $\mathrm{MCH}^{+}$neurons were detected in the NEP, although only in ethanolexposed embryos with a denser concentration of these neurons in the mHYP. Thus, similar to its effect in the LH [11], maternal ethanol significantly increased in the embryo mRNA expression of $\mathrm{MCH}$, more strongly in females than males, and the density of $\mathrm{MCH}$ neurons in both the NEP and mHYP of females.
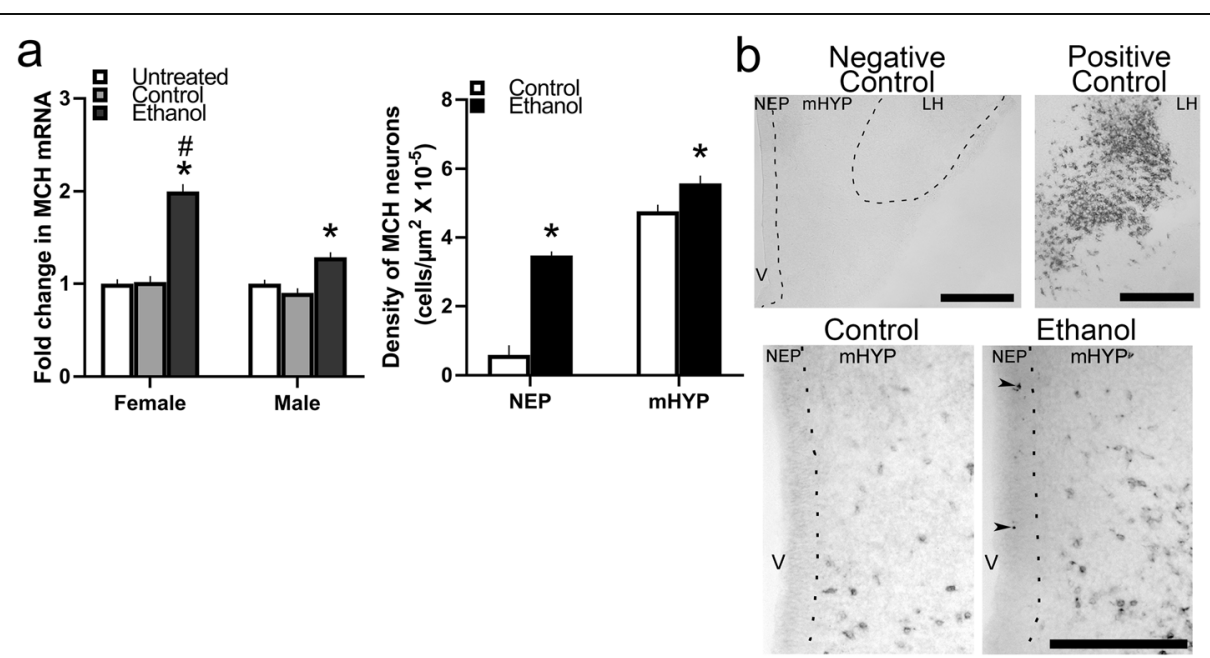

Fig. 8 Stimulatory effects of ethanol on MCH expression and neurons in NEP and mHYP. Maternal ethanol administration group (2 g/kg/day, E10E15) was compared to Untreated and isocaloric Control groups of embryos at E19. a Ethanol compared to control groups significantly increased in NEP+mHYP area mRNA expression of MCH measured using qRT-PCR which is presented here as mRNA fold change compared to Untreated control group. This effect on MCH mRNA levels (determined by analysis of average ratio scores) was evident in both female embryos (Untreated $=2.50 \times 10^{-3}$, Control $=2.25 \times 10^{-3}$, Ethanol $=4.99 \times 10^{-3}$ ) and male embryos (Untreated $=2.62 \times 10^{-3}$, Control $=2.36 \times 10^{-3}$, Ethanol $=3.37 \times$ $10^{-3}$ ) but was significantly greater in females. In a separate set of embryos, ethanol compared to the Control group ( $n=6 /$ group) significantly increased in females the density of $\mathrm{MCH}^{+}$neurons in both the NEP and $\mathrm{mHYP}$ as measured using DIG-ISH. $\mathbf{b}$ This effect on $\mathrm{MCH}^{+}$neurons is illustrated in representative $\times 10$ images of $\mathrm{MCH}$-expressing neurons revealed by DIG-ISH, with several neurons detected in the NEP of ethanoltreated embryos (two most distinct $\mathrm{MCH}^{+}$neurons identified by black arrowheads) but none evident in Control embryos, and with the far denser population in the mHYP also significantly stimulated by ethanol (bottom panel). Top panel shows the negative and positive controls for MCH DIG-ISH. Data are mean \pm SEM. ( $n=7 /$ group/sex, ${ }^{*} p<0.05$ versus control group, ${ }^{\#} p<0.05$ versus males). Two-way ANOVA was used to compare means between groups and simple main effect analyses to test differences between sexes as well as differences within each sex. $\mathrm{mHYP}$, medial hypothalamus; MCH, melanin-concentrating hormone; NEP, neuroepithelium; $V$, third ventricle. Scale bar, $100 \mu m$ 
Maternal ethanol increases the number and percentage of $\mathrm{MCH}$ neurons close to radial glia in NEP and $\mathrm{mHYP}$ of embryos

We next determined whether the appearance and patterning of $\mathrm{MCH}^{+}$neurons are linked to the ethanol-induced stimulation of radial glia cells and processes. We employed a combination of DIG-ISH to label $\mathrm{MCH}^{+}$neurons and IF to label $\mathrm{BLBP}^{+}$radial glia in female embryos of dams that received daily intraoral administration (from E10 to E15) of either $2 \mathrm{~g} / \mathrm{kg} /$ day of ethanol (Ethanol) or an isocaloric maltose-dextrin control solution (Control), and quantified the $\mathrm{MCH}^{+}$neurons as they relate to the radial glia (described in the "Methods" section). Replicating the results described above, we found Ethanol compared to Control to increase the density of $\mathrm{MCH}^{+}$neurons in the NEP $(p<0.001)$ and the mHYP $(p=0.034)$ and also to increase the density of $\mathrm{BLBP}^{+}$cells in the NEP $(p=0.026)$ and $\mathrm{BLBP}^{+}$processes in the $\mathrm{mHYP}(p=0.048)$ (Table 8$)$. With the combination of DIG-ISH and BLBP IF, we discovered in female embryos from a separate set of dams that the individual $\mathrm{MCH}^{+}$neurons are closely related to the radial glia in both the NEP and MHYP, as illustrated most clearly in the photomicrographs of ethanol-exposed embryos (Fig. 9). In the NEP where the $\mathrm{MCH}^{+}$neurons are relatively sparse, Ethanol compared to Control group significantly increased their number along the edge of this midline region, from 0.0 to $4.14 \pm 0.34$ cells $(t(12)=-$ $12.182, p<0.001)$, in the area just lateral to the radial glia cells. Moreover, in the mHYP where the $\mathrm{MCH}^{+}$neurons are more abundant, ethanol also significantly increased their number, from $112.0 \pm 3.53$ to $134.0 \pm 5.31$ cells $(t(12)=-3.359, p=0.006)$, in the area of the radial glia processes. This increase occurred in both the number of $\mathrm{MCH}^{+}$neurons, from $9.29 \pm 0.61$ to $21.00 \pm 0.98(t(12)=$ $110.20, p<0.001)$, and the percentage of total $\mathrm{MCH}^{+}$ neurons, from $8.31 \pm 0.53$ to $16.02 \pm 1.00 \%(t(12)=-$ $6.638, p<0.001)$, that are positioned close to and along the $\mathrm{BLBP}^{+}$processes as they project laterally through the mHYP toward the LH (Fig. 9a). These effects of ethanol are clearly evident in the enlarged image showing three $\mathrm{MCH}^{+}$neurons (white arrowheads) along a single radial glia process (white arrows) in the mHYP (Fig. 9b). We confirmed this anatomical relationship between $\mathrm{MCH}^{+}$ neurons and a distinct $\mathrm{BLBP}^{+}$process using doublelabeled IF for BLBP and $\mathrm{MCH}$ and found in the $\mathrm{mHYP}$ and $\mathrm{LH}$ of an ethanol-exposed embryo a rich concentration of the radial glia processes (but few cells) and the $\mathrm{MCH}^{+}$neurons (Fig. 9c). Many of these $\mathrm{MCH}^{+}$neurons (green) were located close to the radial glia processes (red), as illustrated by the six neurons (white arrowheads) along a single $\mathrm{BLBP}^{+}$process (white arrows). These results suggest that the stimulatory effect of ethanol on the density of $\mathrm{MCH}^{+}$neurons originates within the embryonic NEP in close relation to the radial glia cells, and it involves the radial glia processes, along which the $\mathrm{MCH}$ neurons are positioned as they project laterally through the $\mathrm{mHYP}$ and continue into the $\mathrm{LH}$, their final destination.

\section{Discussion}

Studies to date of radial glia have shown that prenatal exposure to ethanol, generally administered at chronic high doses, causes morphological and functional defects in these progenitor cells, decreasing their density and disrupting their function in promoting the differentiation and migration of neurons $[30,50]$. Our results here, with ethanol administered at a moderate dose during a brief period of rapid neurogenesis, demonstrate a strong stimulatory effect on the expression and density of $\mathrm{BLBP}^{+}$radial glia cells concentrated in the hypothalamic NEP along the third ventricle, suggesting that the level of mRNA per cell may be increased, and also on the expression and density of their processes projecting laterally through the mHYP and into the LH. These effects, indicating a site and mechanism through which increased neurogenesis and neuronal migration may be induced by ethanol, are consistent with in vitro studies showing relatively low concentrations to stimulate the appearance of radial glia-like precursors and the migration of differentiating neurons $[51,52]$.

Neuroimmune factors including chemokines in the brain are shown to be rich in the embryonic NEP and suggested to play a role in neural development [53]. Whereas most studies have focused on the inflammatory CXCL12/CXCR4 system and its function in stimulating neural stem cell differentiation and neuronal migration $[54,55]$, the CCL2/CCR2 system shown to be expressed

Table 8 Effects of ethanol on MCH and BLBP cells and processes in NEP and mHYP of female embryos

\begin{tabular}{llll}
\hline Labeled cells/processes & Location & Control (cells, objects $\left./ \mu m^{2}\right)$ & Ethanol $\left(\right.$ cells, objects/ $\left.\mu m^{2}\right)$ \\
\hline $\mathrm{MCH}^{+}$ & NEP & $3.77 \mathrm{E}-6 \pm 2.47 \mathrm{E}-6$ & $2.58 \mathrm{E}-5 \pm 2.18 \mathrm{E}-6^{*}$ \\
& mHYP & $4.21 \mathrm{E}-5 \pm 1.89 \mathrm{E}-6$ & $4.92 \mathrm{E}-5 \pm 2.31 \mathrm{E}-6^{*}$ \\
$\mathrm{BLBP}^{+}$ & NEP & $1.09 \mathrm{E}-4 \pm 7.76 \mathrm{E}-6$ & $1.31 \mathrm{E}-4 \pm 6.44 \mathrm{E}-6^{*}$ \\
& mHYP & $1.37 \mathrm{E}-4 \pm 6.99 \mathrm{E}-6$ & $1.65 \mathrm{E}-4 \pm 8.69 \mathrm{E}-6^{*}$
\end{tabular}

Maternal administration of ethanol ( $2 \mathrm{~g} / \mathrm{kg} /$ day, E10-E15) was compared to isocaloric maltose-dextrin control solution (Control) group in the NEP and mHYP areas of female embryos, measured using DIG-labeled in situ hybridization and immunofluorescence histochemistry. Data are mean \pm SEM. $n=6 /$ group, ${ }^{*} p<0.05$ versus Control. One-way ANOVA was used to compare group means followed by SDS post hoc test.

$B L B P$ brain lipid-binding protein, $M C H$ melanin-concentrating hormone, $m H Y P$ medial hypothalamus, NEP hypothalamic neuroepithelium 


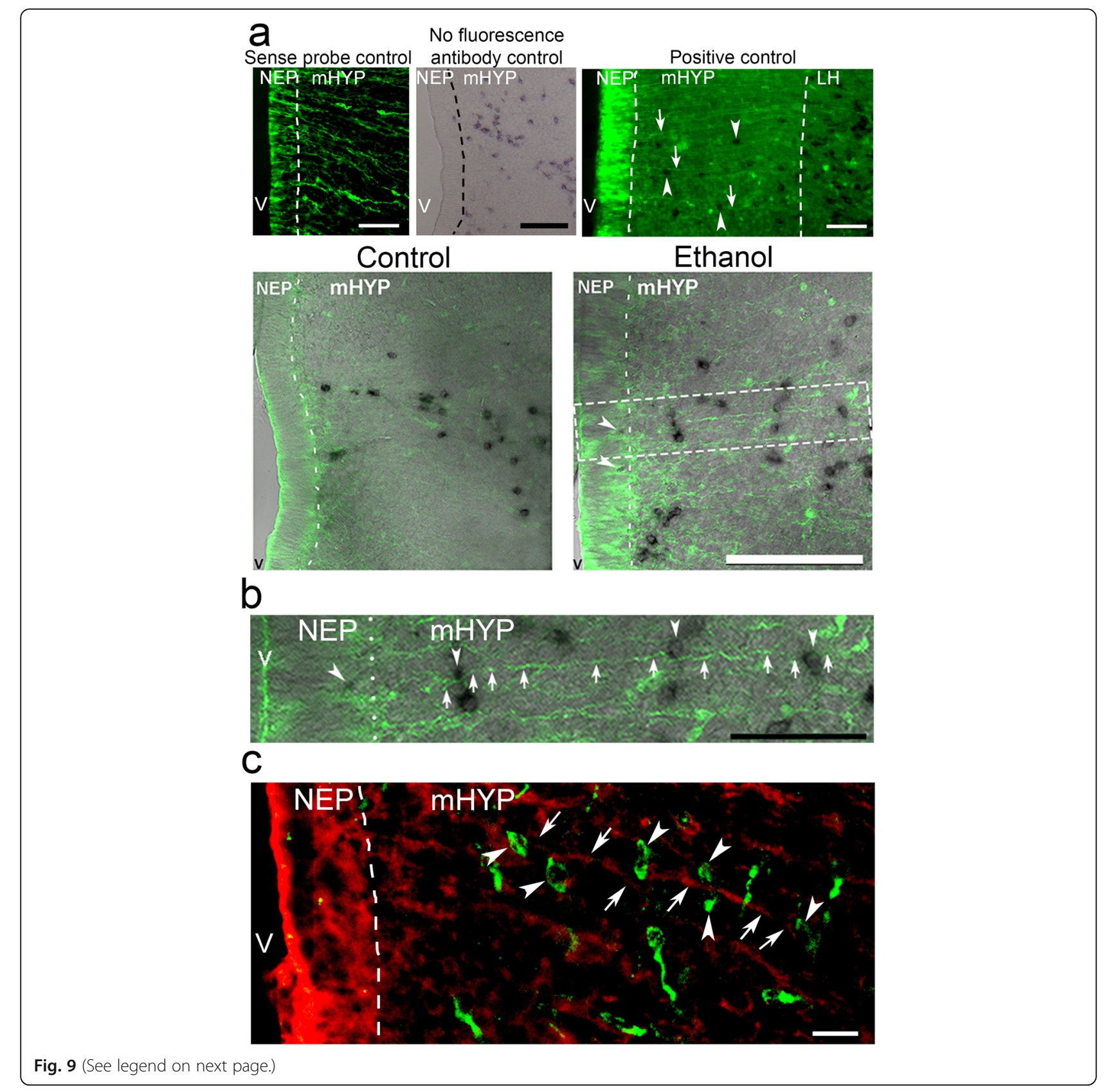


(See figure on previous page.)

Fig. 9 Increased $\mathrm{MCH}^{+}$neurons closely related to radial glia cells and processes in NEP and mHYP. Photomicrographs illustrate how maternal ethanol administration ( $2 \mathrm{~g} / \mathrm{kg} /$ day, E10-E15) compared to isocaloric Control group ( $n=7 / \mathrm{group}$ ) increases the number of $\mathrm{MCH}^{+}$neurons in close relation to the radial glia cells and along their processes (measured by IF for BLBP ${ }^{+}$) in female E19 embryos, with the quantification and data described in detail in the "Methods" and "Results" section. a Top panel, negative controls (sense probe and no fluorescence antibody) and positive control (double-labeling of MCH DIG-ISH with BLBP IF) ( $\times 10$ regular fluorescence images). The sense probe control revealed no MCHexpressing neurons, and the no fluorescence antibody control revealed no BLBP immunofluorescent cells and processes. The positive control shows the MCH-expressing neurons (black) to be very dense in the LH, with some evident in the mHYP (indicated by white arrowheads) and a few in the NEP, and the BLBP-labeled cells (green) to be most concentrated in NEP while their processes (green) are densest in the mHYP (indicated by white arrows) as they project laterally toward the LH. Bottom panel, photomicrographs combining DIG-labeled in situ hybridization for $\mathrm{MCH}^{+}$neurons and immunofluorescence histochemistry for $\mathrm{BLBP}^{+}$radial glia ( $\times 20$ confocal images). In ethanol-exposed embryo compared to control, these images illustrate several $\mathrm{MCH}^{+}$neurons (two indicated by white arrowheads) in NEP, not evident in Control, that lie lateral to the $\mathrm{BLBP}^{+}$radial glia cells and the increased number and percentage of $\mathrm{MCH}^{+}$neurons in $\mathrm{mHYP}$ that are positioned close to the radial glia processes as they project laterally toward LH (see text for data). $\mathbf{b}$ This close relationship between the $\mathrm{MCH}^{+}$neurons and radial glia is more clearly illustrated in the enlarged image (from the area between dotted white lines in of ethanol-exposed embryo), showing one $\mathrm{MCH}^{+}$neuron in the NEP and three $\mathrm{MCH}^{+}$neurons (white arrowheads) along of a single BLBP+ process (white arrow) projecting laterally through the mHYP. $\mathbf{c}$ Further analyses using double-labeled immunofluorescence histochemistry confirmed this close relationship between embryonic $\mathrm{MCH}^{+}$neurons (green) and radial glia (red) in the $\mathrm{mHYP}$, with $\times 40$ image showing six $\mathrm{MCH}^{+}$neurons (white arrowheads) along a single $\mathrm{BLBP}^{+}$process (white arrows) projecting toward the LH. BLBP, brain lipid-binding protein; $\mathrm{MHYP}$, medial hypothalamus; MCH, melanin-concentrating hormone; NEP,

neuroepithelium; $\vee$, third ventricle. Scale bars, $100 \mu \mathrm{m}$

in the embryonic hypothalamus [56] and LH [12] also appears to be involved. There is evidence that CCL2 in vitro stimulates the proliferation, differentiation, and migration of cultured neural progenitor cells $[57,58]$ and the migration of hypothalamic embryonic neurons in cell culture [59] and that knockout of the CCL2 gene disrupts neural progenitor cell migration [60]. We demonstrate here that CCL2 cells in E19 embryos are densely concentrated in the hypothalamic NEP along the third ventricular border with short processes extending laterally into the mHYP, and that these cells and processes are stimulated by moderate maternal administration of ethanol and similarly by maternal administration of CCL2 itself while blocked by a CCR2 antagonist. These new findings focus attention on the hypothalamic NEP as a site where neurons in the LH expressing CCL2 and CCR2 are born $[11,12]$. Together with in vitro studies $[61,62]$ and our reports showing maternal CCL2 administration to increase CCL2 cell density in the NEP as shown here and in the LH $[11,12]$ and central injection of CCL2 to stimulate CCL2 in radial glia cells and processes in embryonic NEP [63], they reveal an autoregulatory mechanism that involves an increase in the synthesis of CCL2 [63].

Our results also suggest that the fetal CCL2/CCR2 system promotes neuronal development as it functions within the radial glia neuroprogenitor cells in the hypothalamic NEP and their long processes projecting laterally through the mHYP and into the LH. They demonstrate that CCL2 colocalizes extensively with these $\mathrm{BLBP}^{+}$radial glia cells and processes, consistent with evidence in the spinal cord [32], and that maternal ethanol at moderate levels markedly stimulates CCL2 in the radial glia and also in local neurons but not microglia, similar to that described in the $\mathrm{LH}$ in our prior studies [11, 12]. These new findings confirm the idea that CCL2 plays many roles during development as it is found in different cell types, including radial glia and neurons. Furthermore, the evidence presented in this report shows that these effects of maternal ethanol are similar to the effects of maternal administration of CCL2 and are reversed by a CCR2 antagonist supporting the idea that the CCL2/CCR2 system in the hypothalamic NEP when stimulated by ethanol in the embryo functions synergistically with and within the radial glia neuroprogenitor cells and processes to promote the differentiation and migration of neurons, including those shown to express CCL2 or CCR2 in the LH [12]. With BLBP in addition to being a radial glia marker also shown to be required for radial elongation [64], a possible involvement of BLBP itself in these stimulatory effects of ethanol and CCL2 on the radial glia processes cannot be excluded.

Our analyses of the $\mathrm{MCH}$ neurons show them to be closely related to the radial glia, both their cells and processes, in the E19 embryo. In this report, maternal ethanol administration from E10 to E15, which overlaps the period of $\mathrm{MCH}$ neurogenesis [65], increases both mRNA expression and density of $\mathrm{MCH}$ neurons in the NEP immediately lateral to the radial glia progenitor cells from which most hypothalamic neurons are suggested to originate [24]. These findings again focus attention on the embryonic NEP, specifically on its CCL2-expressing radial glia cells, as a site highly sensitive to ethanol's inflammatory actions and a source of the increased $\mathrm{MCH}$ neurons detected locally. With radial glial processes known to provide scaffolding in the embryo to facilitate the migration of neurons to outer brain regions $[29,66]$, our additional findings here that ethanol increases the number of $\mathrm{MCH}$ neurons positioned along and in close 
contact with the long CCL2-colocalizing radial glia processes projecting laterally through the mHYP support their role in guiding these neuroepithelial peptide neurons toward their final destination, which is mainly the LH [67]. With radial glia progenitor cells highly active in the embryo but lost shortly after birth [68] and ethanol's effects on glial precursor cells found to cause long-term changes in neuronal development and function [6], ethanol-induced increase in CCL2-rich radial glia progenitor cells and processes described in this report is likely to be an important component of the early developmental phenomena ultimately leading to the increased density in postnatal and adolescent offspring of $\mathrm{MCH}$ neurons in $\mathrm{LH}$ that co-express CCL2 and CCR2 [11, 12, 15].

The sexually dimorphic nature of ethanol's stimulatory effects in the NEP, with greater changes consistently observed in female embryos, is of particular interest since it was previously observed in LH in our prior studies where maternal ethanol similarly stimulated CCL2/ CCR2 system and $\mathrm{MCH}$ neurons in the embryo and adolescent offspring $[11,12,15]$. The most notable finding in this report is that CCL2/CCR2 system in the NEP while strongly stimulated by ethanol in female embryos is totally unresponsive in males, a stark contrast that is consistent with measurements of gene expression reported in the fetal cortex and hippocampus [69]. While there is limited evidence suggesting sexual dimorphism in neuroimmune systems that affect neuronal differentiation [69-71], the dramatic sex differences revealed here in the embryo, possibly reflecting effects of sex hormones and enzymes known to stimulate neurogenesis $[72,73]$, focus attention on the CCL2/CCR2 system in neuroprogenitor cells of the hypothalamic NEP as a key mechanism underlying ethanol's sexually dimorphic, stimulatory effects on neuronal development. This includes the birth and migration of neurons expressing CCL2, CCR2, and $\mathrm{MCH}$ that become concentrated in the LH and remain increased even in adolescent offspring $[11,15]$.

\section{Conclusions}

In summary, the results of this study suggest a novel mechanism in the embryo through which maternal ethanol administration at low-to-moderate doses causes lasting alterations in neuronal systems of the offspring. This mechanism, schematically illustrated in Fig. 10, involves the stimulation of CCL2/CCR2 signaling and radial glia neuroprogenitor cells in the NEP that function together to promote the development of $\mathrm{MCH}$ neurons and also the stimulation of CCL2-expressing radial glia processes in the MHYP that facilitate the migration of $\mathrm{MCH}$ neurons toward the LH where they colocalize CCL2 and CCR2. Further fate-mapping studies of this embryonic neural mechanism in the hypothalamus, as described for microglia [74], should help to determine the precise origin of the $\mathrm{MCH}$ neurons from CCL2-expressing radial glia and characterize in greater depth the mechanisms through which early ethanol exposure directly impacts neuronal development. These findings in the embryo have important clinical significance. Studies in humans as well as animals show maternal ethanol consumption and neuroinflammation during pregnancy to increase alcohol intake in the offspring $[2,4,75]$ and suggest a role for $\mathrm{MCH}$ in reward, alcohol overconsumption, and increased risk for alcohol abuse $[18,76]$. With $\mathrm{MCH}$ also known to have a significant role in the sleep/wake cycle [77], this neuropeptide when stimulated by maternal ethanol exposure may contribute to the disturbances in sleep commonly associated with alcohol use disorder [78]. Further, evidence that the ethanol-induced effects

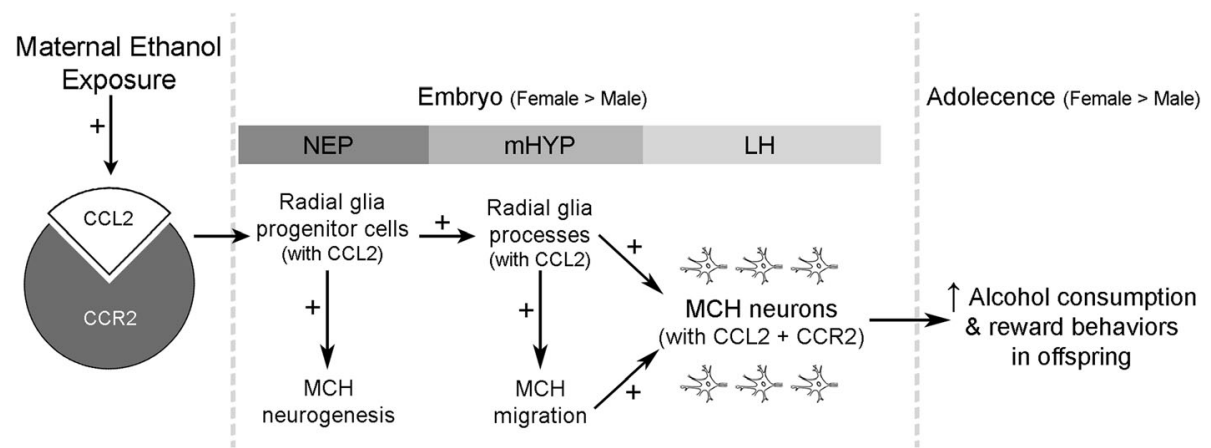

Fig. 10 Schematic representation of proposed neuroimmune mechanism underlying the stimulatory effect of maternal ethanol exposure at a moderate dose on early development of MCH neurons and ultimately on the offspring's behavior. Maternal ethanol exposure (2 g/kg/day, E10E15) increases CCL2 signaling at its receptor CCR2, which in turn stimulates radial glia progenitor cells with CCL2 in the NEP that function to promote MCH neurogenesis in the NEP and also radial glia processes with CCL2 in the MHYP that facilitate the migration of MCH neurons toward the LH where they themselves colocalize CCL2 and CCR2. These molecular changes in the embryo, consistently stronger females than males, may contribute to the increased alcohol consumption and reward behaviors observed later in adolescent offspring, often more strongly in females. LH, lateral hypothalamus; MCH, melanin-concentrating hormone; mHYP, medial hypothalamus; NEP, neuroepithelium 
on $\mathrm{MCH}$ neurons as well as behavior occur more strongly in females than males $[11,12,15]$ and $\mathrm{MCH}$ in females but not males is expressed in the laterodorsal tegmentum [79] that is involved in reward-related behavior [80], may have implications for understanding the increased risk factors for alcohol abuse described in women [81, 82]. Together, this evidence further supports $\mathrm{MCH}$ as a potential therapeutic target for preventing the emergence and relapse of alcohol use disorder $[13,17]$.

\section{Abbreviations}

MCH: Melanin-concentrating hormone; LH: Lateral hypothalamus;

CCL2: Chemokine C-C motif ligand 2; CCR2: CCL2 receptor; E10, E15,

E19: Embryonic day 10, embryonic day 15, embryonic day 19; qRT-

PCR: Quantitative real-time polymerase chain reaction; NEP: Neuroepithelium; mHYP: Medial hypothalamus; IF: Immunofluorescence histochemistry; BLBP: Brain lipid-binding protein; NeuN: Neuronal marker; Iba-1: Microglial marker; CXCL12: C-X-C motif chemokine 12; CXCR4: C-X-C chemokine receptor type 4

\section{Acknowledgements}

The authors thank Ms. Gazal Gulati for her assistance with the figures, tables, and references. We also extend gratitude to The Rockefeller University's BioImaging Resource Center and Translational Technology Core Laboratory for the use of their equipment.

\section{Authors' contributions}

G-QC designed and performed most experiments. OK performed some experiments and data analysis. DB played a major role in writing of the manuscript. SL conceived the experiments and wrote the manuscript. All authors read and approved the final manuscript.

\section{Funding}

This research was supported by the National Institute on Alcohol Abuse and Alcoholism of the National Institutes of Health (award number R01AA024798).

\section{Availability of data and materials}

The datasets used and/or analyzed during the current study are available from the corresponding author on reasonable request.

\section{Ethics approval and consent to participate}

All procedures were conducted in a fully accredited AAALAC facility in accordance with protocols approved by The Rockefeller University Animal Care and Use Committee and consistent with the NIH Guide to the Care and Use of Laboratory Animals.

\section{Consent for publication}

Not applicable.

\section{Competing interests}

The authors declare that they have no competing interests.

Received: 19 December 2019 Accepted: 16 June 2020

Published online: 10 July 2020

\section{References}

1. Alati R, Al Mamun A, Williams GM, O'Callaghan M, Najman JM, Bor W. In utero alcohol exposure and prediction of alcohol disorders in early adulthood: a birth cohort study. Arch Gen Psychiatry. 2006;63:1009-16.

2. Fabio MC, Macchione AF, Nizhnikov ME, Pautassi RM. Prenatal ethanol increases ethanol intake throughout adolescence, alters ethanol-mediated aversive learning, and affects mu but not delta or kappa opioid receptor mRNA expression. Eur J Neurosci. 2015;41:1569-79.

3. Caputo C, Wood E, Jabbour L. Impact of fetal alcohol exposure on body systems: a systematic review. Birth Defects Res C Embryo Today. 2016;108: 174-80.
4. Baer JS, Sampson PD, Barr HM, Connor PD, Streissguth AP. A 21-year longitudinal analysis of the effects of prenatal alcohol exposure on young adult drinking. Arch Gen Psychiatry. 2003;60:377-85.

5. Malone SM, McGue M, lacono WG. Mothers' maximum drinks ever consumed in 24 hours predicts mental health problems in adolescent offspring. J Child Psychol Psychiatry. 2010;51:1067-75.

6. Guizzetti M, Zhang X, Goeke C, Gavin DP. Glia and neurodevelopment: focus on fetal alcohol spectrum disorders. Front Pediatr. 2014;2:123.

7. Komada M, Hara N, Kawachi S, Kawachi K, Kagawa N, Nagao T, Ikeda Y. Mechanisms underlying neuro-inflammation and neurodevelopmental toxicity in the mouse neocortex following prenatal exposure to ethanol. Sci Rep. 2017;7:4934.

8. Mooney SM, Miller MW. Prenatal exposure to ethanol affects postnatal neurogenesis in thalamus. Exp Neurol. 2010;223:566-73.

9. Chang GQ, Karatayev O, Liang SC, Barson JR, Leibowitz SF. Prenatal ethanol exposure stimulates neurogenesis in hypothalamic and limbic peptide systems: possible mechanism for offspring ethanol overconsumption. Neuroscience. 2012;222:417-28.

10. Skorput $A G$, Yeh $\mathrm{HH}$. Effects of ethanol exposure in utero on Cajal-Retzius cells in the developing cortex. Alcohol Clin Exp Res. 2015;39:853-62.

11. Chang GQ, Karatayev O, Halkina V, Edelstien J, Ramirez E, Leibowitz SF Hypothalamic CCL2/CCR2 chemokine system: role in sexually dimorphic effects of maternal ethanol exposure on melanin-concentrating hormone and behavior in adolescent offspring. J Neurosci. 2018;38:9072-90.

12. Chang GQ, Karatayev O, Devi Sai Sri Kavya B, Leibowitz SF: CCL2/CCR2 chemokine system in embryonic hypothalamus: involvement in sexually dimorphic stimulatory effects of prenatal ethanol exposure on peptideexpressing neurons. Neuroscience 2020, 424:155-171.

13. Karlsson C, Rehman F, Damadzic R, Atkins AL, Schank JR, Gehlert DR, Steensland $\mathrm{P}$, Thorsell A, Heilig M. The melanin-concentrating hormone-1 receptor modulates alcohol-induced reward and DARPP-32 phosphorylation. Psychopharmacology (Berl). 2016;233:2355-63.

14. Diniz GB, Bittencourt JC. The melanin-concentrating hormone as an integrative peptide driving motivated behaviors. Front Syst Neurosci. 2017; $11: 32$

15. Chang GQ, Karatayev O, Leibowitz SF. Prenatal exposure to ethanol stimulates hypothalamic CCR2 chemokine receptor system: possible relation to increased density of orexigenic peptide neurons and ethanol drinking in adolescent offspring. Neuroscience. 2015;310:163-75.

16. Duncan EA, Proulx K, Woods SC. Central administration of melaninconcentrating hormone increases alcohol and sucrose/quinine intake in rats. Alcohol Clin Exp Res. 2005;29:958-64.

17. Cippitelli A, Karlsson C, Shaw JL, Thorsell A, Gehlert DR, Heilig M. Suppression of alcohol self-administration and reinstatement of alcohol seeking by melanin-concentrating hormone receptor 1 (MCH1-R) antagonism in Wistar rats. Psychopharmacology (Berl). 2010;211:367-75.

18. Morganstern I, Chang GQ, Chen YW, Barson JR, Zhiyu Y, Hoebel BG, Leibowitz SF. Role of melanin-concentrating hormone in the control of ethanol consumption: region-specific effects revealed by expression and injection studies. Physiol Behav. 2010;101:428-37.

19. Drew PD, Kane CJ. Fetal alcohol spectrum disorders and neuroimmune changes. Int Rev Neurobiol. 2014;118:41-80.

20. Vetreno RP, Crews FT. Current hypotheses on the mechanisms of alcoholism. Handb Clin Neurol. 2014;125:477-97.

21. Zhang K, Luo J. Role of MCP-1 and CCR2 in alcohol neurotoxicity. Pharmacol Res. 2019;139:360-6.

22. Pascual M, Montesinos J, Montagud-Romero S, Forteza J, Rodriguez-Arias M, Minarro J, Guerri C. TLR4 response mediates ethanol-induced neurodevelopment alterations in a model of fetal alcohol spectrum disorders. J Neuroinflammation. 2017;14:145.

23. Banisadr G, Gosselin RD, Mechighel P, Kitabgi P, Rostene W, Parsadaniantz SM. Highly regionalized neuronal expression of monocyte chemoattractant protein-1 (MCP-1/CCL2) in rat brain: evidence for its colocalization with neurotransmitters and neuropeptides. J Comp Neurol. 2005;489:275-92.

24. Bedont JL, Newman EA, Blackshaw S. Patterning, specification, and differentiation in the developing hypothalamus. Wiley Interdiscip Rev Dev Biol. 2015;4:445-68.

25. Allen NJ, Lyons DA. Glia as architects of central nervous system formation and function. Science. 2018;362:181-5.

26. Campbell K, Götz M. Radial glia: multi-purpose cells for vertebrate brain development. Trends Neurosci. 2002;25:235-8. 
27. Florio $M$, Huttner WB. Neural progenitors, neurogenesis and the evolution of the neocortex. Development. 2014;141:2182-94.

28. Taverna E, Gotz M, Huttner WB. The cell biology of neurogenesis: toward an understanding of the development and evolution of the neocortex. Annu Rev Cell Dev Biol. 2014;30:465-502.

29. Barry DS, Pakan JM, McDermott KW. Radial glial cells: key organisers in CNS development. Int J Biochem Cell Biol. 2014;46:76-9.

30. Aronne M, Guadagnoli T, Fontanet P, Evrard S, Brusco A. Effects of prenatal ethanol exposure on rat brain radial glia and neuroblast migration. Exp Neurol. 2011;229:364-71.

31. Wilhelm CJ, Guizzetti M. Fetal alcohol spectrum disorders: an overview from the glia perspective. Front Integr Neurosci. 2015;9:65.

32. Knerlich-Lukoschus F, von der Ropp-Brenner B, Lucius R, Mehdorn HM Held-Feindt J. Chemokine expression in the white matter spinal cord precursor niche after force-defined spinal cord contusion injuries in adult rats. Glia. 2010;58:916-31.

33. Banisadr G, Rostene W, Kitabgi P, Parsadaniantz SM. Chemokines and brain functions. Curr Drug Targets Inflamm Allergy. 2005;4:387-99.

34. Bilbo SD, Schwarz JM. The immune system and developmental programming of brain and behavior. Frontiers in neuroendocrinology. 2012; 33:267-86.

35. Miceli M, Dell'Aversana C, Russo R, Rega C, Cupelli L, Ruvo M, Altucci L, Chambery A. Secretome profiling of cytokines and growth factors reveals that neuro-glial differentiation is associated with the down-regulation of chemokine ligand 2 (MCP-1/CCL2) in amniotic fluid derived-mesenchymal progenitor cells. PROTEOMICS. 2016;16:674-88.

36. Brischoux F, Fellmann D, Risold PY. Ontogenetic development of the diencephalic $\mathrm{MCH}$ neurons: a hypothalamic 'MCH area' hypothesis. Eur $J$ Neurosci. 2001;13:1733-44.

37. Qiang M, Wang MW, Elberger AJ. Second trimester prenatal alcohol exposure alters development of rat corpus callosum. Neurotoxicol Teratol. 2002;24:719-32

38. Majchrowicz E. Induction of physical dependence upon ethanol and the associated behavioral changes in rats. Psychopharmacologia. 1975;43:24554.

39. Braconi S, Sidhpura N, Aujla H, Martin-Fardon R, Weiss F, Ciccocioppo R. Revisiting intragastric ethanol intubation as a dependence induction method for studies of ethanol reward and motivation in rats. Alcohol Clin Exp Res. 2010;34:538-44.

40. Dansereau MA, Gosselin RD, Pohl M, Pommier B, Mechighel P, Mauborgne A, Rostene W, Kitabgi P, Beaudet N, Sarret P, Melik-Parsadaniantz S. Spinal CCL2 pronociceptive action is no longer effective in CCR2 receptor antagonist-treated rats. J Neurochem. 2008;106:757-69.

41. Van Steenwinckel J, Reaux-Le Goazigo A, Pommier B, Mauborgne A, Dansereau MA, Kitabgi P, Sarret P, Pohl M, Melik Parsadaniantz S. CCL2 released from neuronal synaptic vesicles in the spinal cord is a major mediator of local inflammation and pain after peripheral nerve injury. J Neurosci. 2011;31:5865-75.

42. Anthony TE, Klein C, Fishell G, Heintz N. Radial glia serve as neuronal progenitors in all regions of the central nervous system. Neuron. 2004;41: 881-90.

43. Altman J, Bayer SA. Atlas of Prenatal Rat Brain Development. Boca Raton: CRC Press; 1995

44. Barson JR, Fagan SE, Chang GQ, Leibowitz SF. Neurochemical heterogeneity of rats predicted by different measures to be high ethanol consumers. Alcohol Clin Exp Res. 2013;37:141-51.

45. West NR, Hegazy AN, Owens BMJ, Bullers SJ, Linggi B, Buonocore S, Coccia M, Gortz D, This S, Stockenhuber K, et al. Oncostatin M drives intestinal inflammation and predicts response to tumor necrosis factor-neutralizing therapy in patients with inflammatory bowel disease. Nat Med. 2017;23:579-89.

46. Adachi N, Suzuki S, Matsuoka H, Fushimi S, Ono J, Ohta Kl, Hirai Y, Miki T, Koshimizu H. Corticotropin-releasing hormone-binding protein is upregulated by brain-derived neurotrophic factor and is secreted in an activity-dependent manner in rat cerebral cortical neurons. J Neurochem. 2018;146:99-110

47. Chang GQ, Karatayev O, Leibowitz SF. Prenatal exposure to nicotine stimulates neurogenesis of orexigenic peptide-expressing neurons in hypothalamus and amygdala. J Neurosci. 2013;33:13600-11.

48. Bittencourt JC, Presse F, Arias C, Peto C, Vaughan J, Nahon JL, Vale W, Sawchenko PE. The melanin-concentrating hormone system of the rat brain: an immuno- and hybridization histochemical characterization. J Comp Neurol. 1992;319:218-45.

49. Chang GQ, Gaysinskaya V, Karatayev O, Leibowitz SF. Maternal high-fat diet and fetal programming: increased proliferation of hypothalamic peptideproducing neurons that increase risk for overeating and obesity. J Neurosci. 2008:28:12107-19.

50. Wilhelm CJ, Guizzetti M. Fetal alcohol spectrum disorders: an overview from the glia perspective. Front Integr Neurosci. 2016;9:65

51. Santillano DR, Kumar LS, Prock TL, Camarillo C, Tingling JD, Miranda RC. Ethanol induces cell-cycle activity and reduces stem cell diversity to alter both regenerative capacity and differentiation potential of cerebral cortical neuroepithelial precursors. BMC Neurosci. 2005;6:59.

52. Camarillo C, Miranda RC. Ethanol exposure during neurogenesis induces persistent effects on neural maturation: evidence from an ex vivo model of fetal cerebral cortical neuroepithelial progenitor maturation. Gene Expr. 2008;14:159-71.

53. Mennicken F, Maki R, de Souza EB, Quirion R. Chemokines and chemokine receptors in the CNS: a possible role in neuroinflammation and patterning. Trends Pharmacol Sci. 1999;20:73-8.

54. Mithal DS, Ren D, Miller RJ. CXCR4 signaling regulates radial glial morphology and cell fate during embryonic spinal cord development. Glia. 2013;61:1288-305

55. Abe P, Molnar Z, Tzeng YS, Lai DM, Arnold SJ, Stumm R. Intermediate progenitors facilitate intracortical progression of thalamocortical axons and interneurons through CXCL12 chemokine signaling. J Neurosci. 2015;35: 13053-63.

56. Rosin JM, Kurrasch DM. In utero electroporation induces cell death and alters embryonic microglia morphology and expression signatures in the developing hypothalamus. J Neuroinflammation. 2018;15:181.

57. Liu XS, Zhang ZG, Zhang RL, Gregg SR, Wang L, Yier T, Chopp M. Chemokine ligand 2 (CCL2) induces migration and differentiation of subventricular zone cells after stroke. J Neurosci Res. 2007:85:2120-5.

58. Hong YR, Lee $H$, Park MH, Lee JK, Lee JY, Suh HD, Jeong MS, Bae JS, Jin HK. CCL2 induces neural stem cell proliferation and neuronal differentiation in Niemann-Pick type C mice. J Vet Med Sci. 2015;77(6):693-9.

59. Poon K, Ho HT, Barson JR, Leibowitz SF. Stimulatory role of the chemokine $\mathrm{CCL} 2$ in the migration and peptide expression of embryonic hypothalamic neurons. J Neurochem. 2014;131(4):509-20.

60. Belmadani A, Tran PB, Ren D, Miller RJ. Chemokines regulate the migration of neural progenitors to sites of neuroinflammation. J Neurosci. 2006;26: 3182-91.

61. Harris Q, Seto J, O'Brien K, Lee PS, Kondo C, Heard BJ, Hart DA, Krawetz RJ. Monocyte chemotactic protein-1 inhibits chondrogenesis of synovial mesenchymal progenitor cells: an in vitro study. Stem Cells. 2013;31:2253-65.

62. Sakai N, Wada T, Furuichi K, Shimizu K, Kokubo S, Hara A, Yamahana J, Okumura T, Matsushima K, Yokoyama H. MCP-1/CCR2-dependent loop for fibrogenesis in human peripheral CD14-positive monocytes. Journal of leukocyte biology. 2006;79:555-63.

63. Chang GQ, Karatayev O, Boorgu D, Leibowitz SF. Third ventricular injection of CCL2 in rat embryo stimulates CCL2/CCR2 neuroimmune system in neuroepithelial radial glia progenitor cells: relation to sexually dimorphic, stimulatory effects on peptide neurons in lateral hypothalamus. Neuroscience. 2020. https://doi.org/10.1016/j.neuroscience.2020.01.020.

64. Feng L, Hatten ME, Heintz N. Brain lipid-binding protein (BLBP): a novel signaling system in the developing mammalian CNS. Neuron. 1994;12:895-908.

65. Risold PY, Croizier S, Legagneux K, Brischoux F, Fellmann D, Griffond B. The development of the MCH system. Peptides. 2009;30:1969-72.

66. Jinnou H, Sawada M, Kawase K, Kaneko N, Herranz-Perez V, Miyamoto T, Kawaue T, Miyata T, Tabata Y, Akaike T, et al. Radial glial fibers promote neuronal migration and functional recovery after neonatal brain injury. Cell Stem Cell. 2018;22:128-37 e129.

67. Chometton S, Croizier S, Fellmann D, Risold PY. The MCH neuron population as a model for the development and evolution of the lateral and dorsal hypothalamus. J Chem Neuroanat. 2016;75:28-31.

68. Schmechel DE, Rakic P. Arrested proliferation of radial glial cells during midgestation in rhesus monkey. Nature. 1979;277:303-5.

69. Terasaki LS, Schwarz JM. Effects of moderate prenatal alcohol exposure during early gestation in rats on inflammation across the maternal-fetalimmune interface and later-life immune function in the offspring. J Neuroimmune Pharmacol. 2016;11:680-92. 
70. Alfonso-Loeches S, Pascual M, Guerri C. Gender differences in alcoholinduced neurotoxicity and brain damage. Toxicology. 2013;311:27-34.

71. Pascual M, Montesinos J, Marcos M, Torres JL, Costa-Alba P, Garcia-Garcia F, Laso FJ, Guerri C. Gender differences in the inflammatory cytokine and chemokine profiles induced by binge ethanol drinking in adolescence. Addict Biol. 2017;22:1829-41.

72. Pellegrini E, Diotel N, Vaillant-Capitaine C, Perez Maria R, Gueguen MM, Nasri A, Cano Nicolau J, Kah O. Steroid modulation of neurogenesis: focus on radial glial cells in zebrafish. J Steroid Biochem Mol Biol. 2016;160:27-36.

73. Brocca ME, Garcia-Segura LM. Non-reproductive functions of aromatase in the central nervous system under physiological and pathological conditions. Cell Mol Neurobiol. 2019;39:473-81.

74. Ginhoux F, Greter M, Leboeuf M, Nandi S, See P, Gokhan S, Mehler MF, Conway SJ, Ng LG, Stanley ER, et al. Fate mapping analysis reveals that adult microglia derive from primitive macrophages. Science. 2010;330:841-5.

75. Liu X, Lee JG, Yee SK, Bresee CJ, Poland RE, Pechnick RN. Endotoxin exposure in utero increases ethanol consumption in adult male offspring. Neuroreport. 2004;15:203-6.

76. Dilsiz P, Aklan I, Atasoy NS, Yavuz Y, Gizem Filiz, Koksalar F, Ates T, Oncul M, Coban I, Oz EA, Cebecioglu U, Alp MI, Yilmaz B, Atasoy D. MCH Neuron Activity is Sufficient for Reward and Reinforces Feeding. Neuroendocrinology. 2020;110(3-4):258-70

77. Ono D, Yamanaka A. Hypothalamic regulation of the sleep/wake cycle. Neurosci Res. 2017;118:74-81.

78. Koob GF, Colrain IM. Alcohol use disorder and sleep disturbances: a feedforward allostatic framework. Neuropsychopharmacology. 2020:45:141-65.

79. Ferreira JGP, Bittencourt JC, Adamantidis A. Melanin-concentrating hormone and sleep. Curr Opin Neurobiol. 2017;44:152-8.

80. Coimbra B, Soares-Cunha C, Vasconcelos NAP, Domingues AV, Borges S, Sousa N, Rodrigues AJ. Role of laterodorsal tegmentum projections to nucleus accumbens in reward-related behaviors. Nat Commun. 2019;10: 4138.

81. Foster KT, Hicks BM, lacono WG, McGue M. Gender differences in the structure of risk for alcohol use disorder in adolescence and young adulthood. Psychol Med. 2015;45:3047-58

82. Peltier MR, Verplaetse TL, Mineur YS, Petrakis IL, Cosgrove KP, Picciotto MR, McKee SA. Sex differences in stress-related alcohol use. Neurobiol Stress. 2019;10:100149.

\section{Publisher's Note}

Springer Nature remains neutral with regard to jurisdictional claims in published maps and institutional affiliations.

Ready to submit your research? Choose BMC and benefit from:

- fast, convenient online submission

- thorough peer review by experienced researchers in your field

- rapid publication on acceptance

- support for research data, including large and complex data types

- gold Open Access which fosters wider collaboration and increased citations

- maximum visibility for your research: over $100 \mathrm{M}$ website views per year

At BMC, research is always in progress.

Learn more biomedcentral.com/submissions 